\title{
Aggregate vs Disaggregate Data Analysis - A Paradox in the Estimation of Money Demand Function of Japan Under the Low Interest Rate Policy*
}

\author{
by \\ Cheng Hsiao ${ }^{a, b}$ \\ Yan Shen ${ }^{a}$ \\ Hiroshi Fujikic
}

March 13. 2002

\author{
${ }^{a}$ Department of Economics \\ University of Southern California \\ Los Angeles. CA 90089 \\ ${ }^{b}$ Department of Economics \\ Hong Kong University of Science and Technology \\ Clear Water Bay: Kowloon \\ Hong Kong \\ Institute of Monetary and Economic Studies \\ Bank of Japan \\ CPO Box 203 \\ Tokyo 100-8630. JAPAX
}

\begin{abstract}
* We would like to thank O. Ashenfelter. P. Evans. C. Granger, L. Klein. J.H. McCulloch. A. Zellner. participants of Delaware. University of Pennsylvania, Vanderbilt. Ohio State. University of Southern California econometrics workshop and Econometric Society Far East Meeting in Kobe for helpful comments and discussions. We would also like to thank Professor A.K. Tahmiscioglu for kindly making available the computer programs he developed for estimating dynamic panel data models. We would also like to tharl the Institute of Monetary and Economic Studies. Bank of Japan for the hospitality and research assistance.
\end{abstract}




\begin{abstract}
We investigate the issue of whether there was a stable money demand function for Japan in $1990^{\circ} \mathrm{s}$ using both aggregate and disaggregate time series data. The aggregate data appears to support the contention that there was no stable money demand function. The disaggregate data shows that there was a stable money demand function. Neither was there any indication of the presence of liquidity trap. Possible sources of discrepancy are explored and the diametrically opposite results between the aggregate and disaggregate analysis are attributed to the neglected heterogeneity among micro units. We also conduct simulation analysis to show that when heterogeneity among micro units is present. the prediction of aggregate outcomes, using aggregate data is less accurate than the prediction based on micro equations. Moreover. policy evaluation based on aggregate data can be grossly misleading.
\end{abstract}




\section{Introduction}

Aggregate and disaggregate data can sometimes yield diametrically opposite information. In this paper we use Japan's aggregate and disaggregate data to analyze the issue of whether there exists a stable money demand function under the low interest rate policy.

Despite very aggressive fiscal and monetary policies, Japan's economy largely stagnated in the $90^{\circ} \mathrm{s}$. The dependence of national budget (ippan kaikei) on the issuance of the bonds on an ongoing basis has reached $38.5 \%$ in the fiscal year 2000 budget, a dramatic increase from 10.6\% in 1990 (Highlights of the Budget for FY 2001 (April 2001)). On a stock basis, the government gross debt to GDP is approximately $135.3 \%$ in 2000 . the worst level among industrialized countries (Fujiki, Okina and Shirutsuka (2001)). Doi (2000), based on the criteria of Bohn (1995), found that Japan`s fiscal position had deteriorated to an unsustainable level. Given that the substainability of fiscal debt is uncertain, it is natural that one might wonder if monetary policy could play a more important role in stimulating Japanese economy: However, the effectiveness of monetary policy depends critically on the existence of a stable money demand function and the nonexistence of liquidity trap.

Nakashima and Saito (2000) analyze monthly aggregate time series data from January, 1985 to 1999 and conclude that (i) there was a structural break in January 1995. (ii) there was no stable relation between money demand and income; and (iii) there was evidence of liquidity trap after 1995. On the other hand. Fujiki, Hsiao and Shen (2001) use panel information of $4 \bar{\tau}$ prefectures of Japan and finds that there is indeed a stable money demand function at the disaggregate level. In this paper we wish to investigate further whether Japan has a stable money demand equation under the low interest rate policy by relying on the evidence of aggregate and disaggregate time series data and explore the source of discrepancy between the information of the aggregate and disaggregate data..

Section 2 presents the basic model for money demand equation. Section 3 presents the evidence of aggregate quarterly time series data from 1980.IV to 2000.IV which basically supports the contention that there was no stable money demand function and money de- 
mand is better modeled as a random walk with a drift. Section 4 uses a random coefficients framework to analyze disaggregate annual time series data of 47 Japanese prefectures from 1985 to 1997 . The evidence appears to support money demand as a stable function of real income and nominal interest rate. Section 5 explores possible sources of discrepancy between the evidence of aggregate and disaggregate time series data and provides arguments in favor of disaggregate data analysis. Section 6 provides simulation results of the relationship between aggregate and disaggregate data. Section 7 uses simulated data to illustrate the importance of relying on disaggregate data to predict the aggregate outcomes and evaluate policy impacts when heterogeneity is present in micro units. Conclusions are in section 8 .

\section{The Basic Formulation}

We assume that the logarithm of the desired real money balance, $m^{*}$, is a linear function of the logarithm of real income, $y$, and nominal interest rate, $r$,

$$
m_{t}^{*}=a^{*}+b^{*} y_{t}+c^{*} r_{t} .
$$

The actual demand for money follows a stock adjustment principle in which the changes in money demand is proportional to the deviation between the desired and actual money holding (Nerlove (1958)),

$$
\left(m_{t}-m_{t-1}\right)=\gamma^{*}\left(m_{t}^{*}-m_{t-1}\right)+\epsilon_{t} .
$$

where $\gamma^{*}$ denotes the speed of adjustment, typically assumed to be $0<\gamma^{*}<1$, and $\epsilon_{t}$ denotes the noise. Substituting (2.1) into (2.2) yields a money demand equation of the form

$$
m_{t}=\gamma m_{t-1}+b y_{t}+c r_{t}+a+\epsilon_{t},
$$

where $\gamma=\left(1-\gamma^{*}\right), b=\gamma^{*} b^{*} \cdot c=\gamma^{*} c^{*}, a=\gamma^{*} a^{*}$.

Eq. (2.2) implies a long-run equilibrium relation between money and income of the form

$$
\bar{m}=\frac{b}{1-\gamma} y+\frac{c}{1-\gamma} r+\frac{a}{1-\gamma} .
$$




\section{Aggregate Time Series Analysis}

In this section we report the results of using Japan's quarterly real M1 (RM1). real M2 (RM2), real GDP(RGDP), and interest rate from 1980.IV - 2000.IV. The interest rates used by Nakashima and Saito (2000) or Fujiki, Hsiao and Shen (2001) are the Bank of Japan overnight call rates. However, as pointed out by L. Klein that the call rate may be too short. Therefore we use five year bond rate $\left(r_{t}\right) .{ }^{1}$ Substituting $m_{t}$ for $\bar{m}$ in (2.4) yields the long-run relation between $m_{t}, y_{t}$ and $r_{t}$ as

$$
m_{t}=\frac{a}{1-\gamma}+\frac{b}{1-\gamma} y_{t}+\frac{c}{1-\gamma} r_{t}+v_{t},
$$

where $v_{t}$ denotes the error term. Inference on (3.1) depends critically on the time series properties of $m_{t}, y_{t}$ and $r_{t}$. We use augmented Dickey-Fuller statistic (ADF) to test if the logarithm of $R M 1, R M 2, R G D P$, and $r_{t}$ are stationary or integrated of certain order. Because there is an issue of whether there is a structural break after the bubble burst in 1990. Table 1 reports the results of ADF using the complete sample and sub-sample period 1992.I - 2000.IV. Both the complete sample and subsample results overwhelmingly favor the hypothesis that they are integrated of order 1. I(1).

Under the assumption that $m_{t}, y_{t}$ and $r_{t}$ are $I(1)$, then the issue of whether there exists a stable money demand equation is an issue of whether there exists a cointegrating relation between $m_{t} . y_{t}$ and $r_{t}$. Table 2 reports Johansen $(1988,91)$ likelihood ratio test results when $m_{t}, y_{t}$ and $r_{t}$ are all treated as $I(1)$. For the complete sample period based on either AIC (Akaike (1973)) or Schwarz (1978) criterion selected order of autoregressive process. there is one cointegration between income, interest rate, and $\mathrm{M} 1$ or M2. Focusing on the subperiod of 1992.I - 2000.IV there is one cointegrating relation between M2. RGDP and $r_{t}$ but no cointegrating relation between M1. RGDP and $r_{t}$.

\footnotetext{
${ }^{1}$ Since our analysis use Japanese GDP data based on 1993 System of National Account (Benchmark year=1995), we can only use data from 1980 to 2000. See details of the revision of Japanese GDP statistics. http://www.esri.cao.go.jp/en/sna/menu.html. Thus our results are not comparable with literature using 1968 System of National Account, such as Mivao (1996). In addition. most Japanese researchers use M2+CD instead of M2. however. since our results will be compared with those using prefecture deposit that do not include CD. we will use $\mathrm{M} 2$.
} 
Table 3 presents the Johansen (1991) normalized cointegrating estimates between $m_{t}, y_{t}$, and $r_{t}$ for both the complete sample and sub-sample period. The complete sample estimated income coefficient for the Ml equation is exactly the opposite of what the economic theory predicts. The income coefficient of M2 although has the correct sign, the interest rate coefficient has the wrong sign. For the subsample period, although estimates of the income coefficients yield correct signs, they are of this unbelievable magnitude with income elasticity of 75.23 for M1 and 11.04 for M2. Moreover, the interest rate coefficients in these equations are of the wrong signs.

The Johansen (1991) MLE of the cointegrating relations is based on the decomposition of the coefficient matrix of the level variables, $\Pi$, into the product of $\Pi=\underset{\sim}{\alpha \beta^{\prime}}$, in an error correction representation of a vector autoregressive model where $\beta_{\sim}^{\prime}$ is referred as the cointegrating relations and $\alpha$ is referred as the adjustment coefficients of the deviations from the long-run equilibrium. However, as argued in Hsiao (2001a) that it is difficult to give a structural interpretation of the cointegrating vectors ${\underset{\sim}{\prime}}^{\prime}$ and it is preferable to view the corresponding row of $\Pi$ directly as the implied long-run relation of the equation of interest. Anderson (2001) has proposed an efficient method of directly estimating $\Pi$ given the rank of cointegration. Table 4 presents Anderson's (2001) reduced rank estimation of $\Pi$ assuming that there is one cointegrating relation for both the bivariate and trivariate system. They again would imply a negative relation between $m$ and $y$. Moreover. the estimated coefficients are close to zero. They appear to support the contention that there is no stable relation between money demand and income.

The efficiency gain of the Johansen (1991) MLE of $\beta^{\prime}$ or Anderson's (2001) reduced rank estimation of $\Pi$ is based on the prior knowledge of known rank of cointegration. However. it is well known that tests for cointegration have very poor finite sample performance. Therefore, in Table 5 we present the unrestricted error-correction estimation of the long-run relations between $m, y$, and $r .^{2}$ The results again confirm the early findings that

${ }^{2}$ The unrestricted error correction estimates are identical to the unrestricted vector autoregressive model estimates with proper linear transformation (e.g. Hsiao (2001a)). 
either the estimated long-run relation is opposite to what economic theory would predict or it is not unreasonable to assume that the corresponding row of $\Pi$ is close to zero after 1992, hence implying that there is no stable relation between money demand and income.

The multivariate time series analysis is very sensitive to the time period covered and the choice of the order of autoregressive process, $p$. We find that either there is no cointegrating relation between money demand and income. or if there is one, the estimated relation is the opposite of what economic theories predict. Therefore, we turn to the single equation modeling. Table 6 presents the least squares estimates of the money demand equation (2.3) for the period 1980.IV - 2000.IV or 1992.I - 2000.IV. The estimated lagged dependent variable coefficient is almost exactly equal to one. The income coefficient is either insignificantly different from zero or has the wrong sign. The interest rate coefficient is statistically significant and has the correct sign. Since neither the multivariate. nor the single equation estimates give economically meaningful interpretation of the money demand equation. we use Box-Jenkins (1970) procedure to model the money demand. Table $T$ presents the ARIMA modeling of $M 1$ and $M 2$.

To check whether the money demand equation of the form (2.3) or the univariate ARIMA model better describes Japan's aggregate money demand, we use the prediction principle. As remarked by Friedman and Schwarz (1991), "the real proof of the pudding is whether it produces a satisfactory explanation of data not used in baking it - data for subsequent or earlier years", we therefore split the sample into two periods. We use data of 1980.IV - 1997.IV to estimate various models. We then use the estimated coefficients to generate one period ahead prediction for the period 1998.I - 2000.IV. The first column of Table 8 presents their root mean square prediction errors. The univariate ARIMA model predicts better than the models that also use income and interest rate as explanatory variables.

The above prediction comparison is based on the data from 1980.IV to 2000.IV. If there is indeed a structural break in the late $80^{\circ} \mathrm{s}$, then the complete sample comparison 
in general favors a random walk model to a vector autoregressive or an error correction model. To gauge against unfavorable treatment of structural models, we also compare the prediction performance by using the data of 1991.III to 1998.II for estimation and generate one period ahead prediction for the period 1998.III to 2000.IV. The root mean square prediction error comparisons are reported at the second column of Table 8. The univariate ARIMA model again dominates the others. The fact that both the prediction results and the estimation of the form (2.3) having coefficients of lagged dependent variable almost exactly equal to one appear to support the contention that Japan's aggregate money demand is better modeled in terms of a random walk with a drift (with a drift parameter possibly changing for period after 1990).

\section{Disaggregate Time Series Analysis}

The fact that Japan's aggregate money demand is better modeled by a random walk with a drift is disconcerting to economists. It basically says that the empirical evidence has refuted theories of money demand (e.g. Laidler (1969)). However, the lack of stable relation between real money demand and real income in aggregate time series analysis could be due to shortages of degree of freedom. But more importantly it could be due to the lack of sample variability. The minimum and maximum value of the logarithm of real GDP is 14.943 and 15.4925 , respectively, for the period $1980 . I V-2000 . I V$ and is 15.3878346 and 15.4925, respectively, for the period 1992.I - 2000.IV. The minimum and maximum value of the logarithm of M1 is 13.6094014 and 14.7069502 , respectively, for the period 1980.IV - 2000.IV, and 14.014138 and 14.7069502, respectively, for the period 1992.I - 2000.IV. The minimum and maximum value of the logarithm of real .M2 is 14.7380118 and 15.7089447, respectively, for the period 1980.IV - 2000.IV and 15.4296417 and 15.7089447 , respectively, for the subperiod 1992.I - 2000.IV. The standard deviations for logarithm of real GDP, real M1 and real M2 are 0.18, 0.31 and 0.29, respectively, for the period 1980.IV - 2000.IV, and are 0.036, 0.23,0.09, respectively, for the period 1992.I - 2000.IV. When all sample points are clustered together, technically any slope coefficient estimates may 
be obtained by slightly changing the time period covered. To get more robust estimate of the relationship between money and income, we need data to vary over a wider range. One possible way to obtain sample of greater variability is to use disaggregate time series. Japan is divided into 47 prefectures. Annual data on prefecture employee income (the counter part to national GDP), prefecture price deflator, population statistics from 1985 1997 are available from the home page of Economic and Social Research Institute (former Economic Planning Agency of Japan). Data on demand deposits (MF1) and MF1+ Saving Deposits (MF2) are available from Monthly Economic Statistics of the Bank of Japan. MF1 and MF2 may be viewed as the prefecture counterpart of the national M1 and M2 without currency held by individuals. (For detail, see Appendix A).

There are several advantages of using disaggregate time series. First, there are more degrees of freedom, more sample variability and less multicollinearity. Figures 1-3 plot the $4 \bar{\imath}$ per capita prefecture real MF1. real MF2 and income over the period $1989-1997$. The minimum and maximum prefecture logarithm of per capita real income is now 2.963 and 3.79, respectively. For the logarithm of real MF1, it is 0.99 and 3.44. For the logarithm of MF2, it is 2.65 and 4.839 , respectively. The standard deviations for logarithm of per capita real income, real MF1 and real MF2 are $0.15,0.37$ and 0.34 , respectively, for the sample period $1989-1997$, and for period 1992 - 1997, the standard deviations are 0.145 , $0.345,0.319$ respectively. Second, it allows more accurate estimate of dynamic adjustment behavior even with a short time series. Third. it provides the possibility to control the impact of omitted variables. Fourth, it provides means to get around structural break tests which are based on large sample theory with dubious finite sample property (e.g. Hsiao (1986, 2001b)).

However. there are also a number of sample and statistical issues of using prefecture data. We shall first discuss issues of data measurement, then statistical modeling. finally present the empirical results.

4a. Data Measurement 
There are three issues involved in using prefecture deposit data in domestically licensed banks. First, there is an issue of consistency of coverage of banks. There was a change in the definition of banks surveyed in the deposit statistics in 1989. Due to an extension of the coverage of regional II banks in the deposit statistics in that year, the Monthly Economic Statistics of the Bank of Japan data show an unusual increase in 1989. Second, there is an issue of whether the bubble burst in 1990 created a noise that can no longer be viewed as random noise from the same population. Third, there is an issue of people living in one prefecture but working in big metropolitan prefectures, Tokyo, Osaka and Kyoto, had bank accounts near where they worked.

With the availability of panel data, it is fairly easy to check if there exist systematic measurement errors on data of some prefectures. To avoid the possibility of obtaining biased results because of inconsistent data measurements in 1989 and 1990, one may just fit a money demand equation for the year 1992 to 1997 . To avoid the problem of people living in one prefecture but having bank accounts in another prefecture, we can exclude the data of Tokyo, Osaka, Kyoto, and their neighboring prefectures Chiba, Saitama, Kanagawa, and Hyogo from considerations and use the remaining 40 prefectures data to fit (2.3).

\section{4b. Statistical Modeling}

Disaggregate data focus on individual outcomes. Factors affecting individual outcomes are numerous. It is neither feasible, nor desirable to construct a model that includes all these factors in the specification. A model is not a mimic of reality. It is a simplification of reality, designed to capture the essential factors affecting the outcomes. To avoid the possibility that heterogeneity among disaggregate units might contaminate the inference of parameters of interest, model (2.3) is modified $\mathrm{as}^{3}$

$$
m_{i t}=\gamma_{i} m_{i, t-1}+b_{i} y_{i t}+c_{i} r_{t}+\alpha_{i}+\epsilon_{i t}, \begin{aligned}
& i=1, \ldots, N \\
& t=1, \ldots, T
\end{aligned}
$$

\footnotetext{
${ }^{3}$ It should be noted that by "individual heterogeneity" we refer to differences between groups that are observable in the context of econometric analysis of individual level data. not the fine distinctions that may characterize each individual differently.
} 
where $m_{i t}, y_{i t}$ denote the logarithm of prefecture per capita real money balance and real income, $r_{t}$ denotes the five year bond rate, $\alpha_{i}$ represents the prefecture specific effects that is supposed to approximate the effects of prefecture rental costs of inputs to the production function of output and financial service and other regional specific effects. The question of whether the coefficients ${\underset{\sim}{i}}_{i}=\left(\gamma_{i}, b_{i}, c_{i}\right)^{\prime}$ should be assumed fixed and different or random and different depends on whether $\theta_{i}$ can be viewed as from heterogeneous population or random draws from a common population. In this paper we shall favor a random coefficients approach for two reasons: First, the short time series dimension does not allow accurate estimation of individual ${\underset{\sim}{i}}_{i}$. Second, if ${\underset{\sim}{i}}_{i}$ are indeed fixed and different, the representative agent argument so frequently used by economists no longer appears relevant. Neither is it possible to make inference about population relationship between money demand, income, and interest rate. Therefore, we assume that the coefficients $\underline{\theta}_{i}^{\prime}=\left(\gamma_{i}, b_{i}, c_{i}\right)$ are randomly distributed with mean $\underset{\sim}{\bar{\theta}}=(\bar{\gamma}, \bar{b}, \bar{c})$ and covariance matrix $\Delta$. When the regional specific effects, $\alpha_{i}$, is treated as a fixed constant, we have a mixed fixed and random effects model (Hsiao and Tahmiscioglu (199i)). When $\alpha_{i}$ is treated as a random variable that is independent of $\left(y_{i t}, r_{t}\right)$ and is independently distributed across $i$ with mean $a$ and variance $\sigma_{\alpha}^{2}$, we have a random coefficients model (e.g. Hsiao (2001b)).

It is well known that when regressors are exogenous the estimators based on the sampling approach yield consistent estimates of the mean coefficients when the number of cross-sectional units approaches infinity. However, the same results do not carry over to dynamic models. The neglect of coefficient heterogeneity in dynamic models creates correlation between the regressors and the error term as well as serial correlation in the residuals. Neither the least squares, nor the within estimator is consistent (Pesaran and Smith (1995)). Moreover, there does not appear possible to find instruments that are correlated with the regressors but are uncorrelated with the error term. Because there does not appear having any consistent estimator of the mean coefficients when $T$ is finite, we shall adopt a hierarchical Bayes estimator which is shown to have very good properties 
in both small and moderate $T$ samples (Hsiao, Pesaran and Tahmiscioglu (1999)) (For detail of the estimation method, see Appendix B).

4c. Empirical Results

We report the finding based on disaggregate data analysis. The first thing we wish to check is that if ${\underset{\sim}{i}}_{i}$ are identical across $i$ as assumed by Fujiki, Hsiao and Shen (2001). The testing of homogeneity across $i$ yields an $F$-value of 69 for MF1 and 4.07 for MF2. Both are statistically significant at $1 \%$ level with 40 and 117 degrees of freedom, hence rejecting the homogeneity assumption.

To check if the issue of people living in one prefecture but having bank accounts in another prefecture might systematically bias the estimation results, we can compare the difference between the estimates using all 47 prefectures and the estimates based on prefecture data that are relatively free from this issue. If the systematic measurement errors are not serious, two estimates are expected to be close. Otherwise, they are expected to be different. Tables 9 and 10 present the random coefficients and mixed fixed and random coefficients estimation of MF1 and MF2 using all 47 prefectures and 40 prefectures. Table 11 presents the Hausman (1978) specification test of the presence of systematic measurement errors. The chi-square statistics reject the null hypothesis of no measurement errors at $1 \%$ significance level in all cases. We therefore concentrate our discussion based on the results using 40 prefectures.

There are three notable features arise from the disaggregate time series analysis. First, while aggregate time series analysis shows that there is no stable relation between money and income, the disaggregate time series analysis shows that there exists a stable money demand function. There is no indication that money demand follows a random walk with a drift. ${ }^{4}$ The estimated mean lagged dependent variable coefficient is significantly below

${ }^{4}$ There is, of course, an issue of temporal aggregation. However, as shown by Tiao (1972) that temporal aggregation does not affect the order of integration of a time series variables. Brewer (1993) also shows that the order of autoregressive process remains the same between temporally aggregate and disaggregate data. It is the order of moving average that might be affected by temporal aggregation. Using Brewer's (1973) formula of rounding down 
one. The mean income coefficient is positive and statistically significant. The estimated mean interest rate coefficient is negative and statistically significant. The estimated mean short-run income coefficients for MF1 and MF2 are 0.88 and $0.4 \bar{i}$, respectively. Both are less than 1. The estimated mean short-run interest rate coefficients for MF1 and MF2 are -0.047 and -0.009 , respectively:

Second, the estimated mean relationship is very similar to those obtained using the formulation of Fujiki. Hsiao and Shen (2001)

$$
\begin{aligned}
m_{i t}=\gamma m_{i . t-1}+b y_{i t}+c r_{t}+\alpha_{i} & +\epsilon_{i t}, \\
i & =1, \ldots, N, \\
t & =1, \ldots, T
\end{aligned}
$$

where $\alpha_{i}$ is assumed either random or fixed (see Table 12, where $\alpha_{i}$ fixed or random is referred to as fixed or random effects estimator, respectively (FE or $R E)$ ). The two formulations provide similar estimates may be due to the estimated variance-covariance matrix of $\theta_{i}$ as summarized at the bottom of Tables 10 and 11 are fairly small in absolute magnitude. In other words, no matter which models we use for the analysis of disaggregate data, they appear to support the contention that there is indeed a stable relation between money demand, income and interest rate as predicted by economic theory.

Third, using the formula of $\frac{\bar{b}}{1-\bar{\gamma}}$ or $\frac{\bar{c}}{1-\bar{\gamma}}$ the estimated long-run income elasticity for MF1 is 2.56 and for MF2 is 1.01, respectively for the random coefficients model and 2.54 and 1.03. respectively for the mixed random and fixed coefficients models. The long-run semi-interest rate for MF1 is -0.138 and for MF2 is -0.019 for the random coefficients model and -0.139 and -0.0189 , respectively for the mixed fixed and random coefficients models. They are similar in magnitude to those obtained from the RE and FE estimates (see Table 13). Using the formula $\sum_{i=1}^{N} \frac{b_{i}}{1-\gamma_{i}} w_{i}$ or $\sum_{i=1}^{N} \frac{c_{i}}{1-\gamma_{i}} w_{i}$, where $w_{i}$ is the average weight of the relative importance of the $i$-th prefecture money demand. the implied average long-run income elasticities for the MF1 and MF2 for the random coefficients model are 2.64 and to the next lowest integer of $(1+0+1) / 4$, we have the same time series model for both aggregate and disaggregate data. 
1.05. respectively, and are 2.62 and 1.06 , respectively for the mixed fixed and random coefficients models.

\section{Possible Source of Discrepancy}

The diametrically opposite evidence obtained from the aggregate and disaggregate data series analysis makes one wonder what constitutes a well grounded level of analytical framework and what are the interesting interactions between disaggregate and aggregate models. In this section we explore if the issues of simultaneity, different definitions of money, and aggregation of heterogeneous units are the reasons behind this conflicting implication.

ja. Simultaneity

In a disaggregate framework it may be plausible to assume that income and interest rate are exogenous, but the same can not be said for the aggregate data. When money, income, and interest rate are jointly determined, least squares regression of the form (2.3) vields biased and inconsistent estimates even though regressors are I(1) (Hsiao (1997a,b)). On the other hand, two stage least squares estimator (2SLS) is consistent. Moreover, the Monte Carlo studies conducted by Hsiao and Wang (2002) have shown that despite the limiting distribution of the 2SLS of a structural vector autoregressive model is not standard normal or mixed normal when there does not exist strictly exogenous driving force, it still dominates modified estimators that possess desirable large sample properties in terms of bias, root mean square error and closeness of the actual size to the nominal size in finite sample. Therefore. we reestimate models of the form (2.3) by the two-stage least squares and present the results in Table 14. Again, the implication is similar to the least squares results. The income coefficients have the wrong signs and the sums of the lagged dependent variable coefficients are almost exactly equal to one. In other words, even after taking account of simultaneity, we still can not find a stable money demand function in the 90 's.

ǰb. Definitions of Money 
Disaggregate time series analysis uses demand deposit (MF1) and demand deposit plus time deposit (MF2) while aggregate time series analysis uses M1 (currency and demand deposit) and M2 (M1 + time deposit). To see if it is the component of currency holding that contributes to the lack of stable relationship between money demand and income, we redo the analysis for the (M1-currency) and (M2-currency). The results of this analysis are similar to those of using M1 and M2 as the dependent variables as can be seen from the least squares and 2SLS estimates presented in Tables 15 and 16.

5c. Aggregation Over Heterogeneous Units

Estimating macro relations always involves aggregation over micro units. Aggregation is valid if the disaggregate relation is linear and if all micro relations have identical parameter values or if the distribution of the micro variables remains constant over time (e.g. Stoker (1993). Theil (1954)). Forni and Lippi (1997, 99), Hildenbrand (1994), Granger (1980). Klein (1953), Lewbel (1992, 94), Pesaran (1999), Stoker (1984, 93). Trivedi (1985). Zaffaroni (2001), etc. have shown that the dynamics of aggregate variables can be very different from the dynamics of disaggregate variables if there exists parameter heterogeneity.

Under the assumption of model (4.1), it is also possible to have stable micro relations but unstable macro relations. Model (4.1) implies that the cointegrating relation of a prefecture takes the form

$$
m_{i t}-\frac{b_{i}}{1-\gamma_{i}} y_{i t}-\frac{c_{i}}{1-\gamma_{i}} r_{t}-\frac{\alpha_{i}}{1-\gamma_{i}}=v_{i t},
$$

where $v_{i t}$ denotes a zero mean $\mathrm{I}(0)$ process. Let $m_{t}=\sum_{i=1}^{N} m_{i t}, y_{t}=\sum_{i=1}^{N} y_{i t}$ and $w_{i t}=y_{i t} / y_{t}$. Then

Proposition 5.1: The aggregate relation $m_{t}-\beta y_{t}-c r_{t}$ is $I(0)$ under the assumption of model (5.2) if and only if either

(i) $\frac{b_{i}}{1-\gamma_{i}}=\frac{b_{j}}{1-\gamma_{j}}$ for all $i$ and $j$ and $\left|\gamma_{i}\right|<1$ for all $i$;

or 
(ii) $w_{i t}=w_{i}$ for all $t$ and $\left|\gamma_{i}\right|<1$ for all $i$.

Proof: From (5.2) we have

$$
\begin{aligned}
m_{t} & -\sum_{i=1}^{N} \frac{b_{i}}{1-\gamma_{i}} y_{i t}-\left(\sum_{i=1}^{N} \frac{c_{i}}{1-\gamma_{i}}\right) r_{t}-\left(\sum_{i=1}^{N} \frac{\alpha_{i}}{1-\gamma_{i}}\right) \\
& =\sum_{i=1}^{N} v_{i t} \\
& =u_{t} .
\end{aligned}
$$

If the long-run relations between $m_{i t}$ and $y_{i t}$ are identical across $i$, then $\frac{b_{i}}{1-\gamma_{i}}=\frac{b_{j}}{1-\gamma_{j}}=\beta$, $c=\sum_{i=1}^{N} \frac{c_{i}}{1-\gamma_{i}}, a=\sum_{i=1}^{N} \frac{\alpha_{i}}{1-\gamma_{i}}$. Since $v_{i t}$ is $I(0), \sum_{i=1}^{N} v_{t}$ is $I(0)$ if all $\left|\gamma_{i}\right|<1$.

Alternatively if $\frac{b_{i}}{1-\gamma_{i}} \neq \frac{b_{j}}{1-\gamma_{j}}$, we can write (5.3) in the form

$$
m_{t}=\left[\sum_{i=1}^{N} \frac{b_{i}}{1-\gamma_{i}} w_{i t}\right] y_{t}+\left(\sum_{i=1}^{N} \frac{c_{i}}{1-\gamma_{i}}\right) r_{t}+\sum_{i=1}^{N} \frac{\alpha_{i}}{1-\gamma_{i}}+\sum_{i=1}^{N} v_{i t} .
$$

It follows that if $w_{i t}=w_{i}$ for all $t$, we have $\beta=\sum_{i=1}^{N} \frac{b_{i}}{1-\gamma_{i}} w_{i}, c=\sum_{i=1}^{N} \frac{c_{i}}{1-\gamma_{i}}, a=\sum_{i=1}^{N} \frac{\alpha_{i}}{1-\gamma_{i}}$, and (ii) holds if $\left|\gamma_{i}\right|<1$.

A sufficient condition for (i) to hold is that $b_{i}=b, \gamma_{i}=\gamma$ and $|\gamma|<1$, then (5.3) becomes

$$
m_{t}-\beta y_{t}-c r_{t}-a=\sum_{i=1}^{N} v_{i t}
$$

where $3=\frac{b}{1-\gamma}, c=\frac{1}{1-\gamma} \sum_{i=1}^{N} c_{i}$ and $a=\frac{1}{1-\gamma} \sum_{i=1}^{N} \alpha_{i}$. Since $v_{i t}$ is $I(0)$, so is $\sum_{i=1}^{N} v_{i t}$. In other words, Proposition 5.1 states that under parameter heterogeneity there could be cases that even though there exist stable relations among micro units, the aggregate relation can still exhibit unit root phenomenon. For instance, if $w_{i t} \neq w_{i s}$, then

$$
m_{t}-\beta y_{t}-c r_{t}-a=\left[\sum_{i=1}^{N} \frac{b_{i}}{1-\gamma_{i}} w_{i t}-\beta\right] y_{t}+\sum_{i=1}^{N} v_{i t} .
$$

Even though all $\left|\gamma_{i}\right|<1$, because $\left[\sum_{i=1}^{N} \frac{b_{i}}{1-\gamma_{i}} w_{i t}-\beta\right] \neq 0$ and because $y_{t}$ is $I(1), m_{t}-$ $3 y_{t}-c r_{t}-a$ will behave like an $I(1)$ process. Alternatively, even $w_{i t}=w_{i}$ for all $i$ and $t$ 
so that the first term on the right-hand side of (5.5) drops out, as long as there is one $\gamma_{i}$ near 1 or equal to 1 . the spectral density of (5.5) becomes unbounded. ${ }^{5}$

Figure $4 \mathrm{a}$ and $4 \mathrm{~b}$ present the distribution of $\gamma_{2}$ for MF1 and MF2. The largest $\gamma_{i}$ for MF1 is 0.87 for Nigata prefecture (about $2.1 \%$ of the total MF1 demand in 1992) and for MF2 is 0.93 for Mie prefecture (slightly above $2.4 \%$ of the total MF2 demand in 1992), hence appears to reject the hypothesis that the instability observed at the aggregate level is due to one of the $\gamma_{i}$ is one or near one. Figure 5 presents the distribution of $w_{i t}$. They do not appear to stay constant over time. This information appears to indicate that micro heterogeneity could be the source of discrepancy between aggregate and disaggregate.

6. A Simulation Study of the Relationship between Aggregate and Disaggregate Behavior Although in section 5 we show that ignoring parameter heterogeneity across prefectures could be the reason of inducing an unstable aggregate money demand function, in our micro specification (4.1) we use a log-linear specification. This implies that aggregation is in effect nonlinear because the aggregate variables are not defined as the sum of variables in logarithms, but are defined as the logarithm of the sum of micro variables. The nonlinear aggregation makes it much more difficult to derive mathematical relationships between aggregate and disaggregate relations. In this section we resort to simulation methods to show that it is indeed possible to generate unit root phenomenon and insignificant income coefficient even when there exist stable relations among micro units if the parameters are different across prefectures and the aggregation is nonlinear.

6a. The Simulation Design

We artificially generate time series data for each prefecture based on the observed

${ }^{5}$ Zaffaroni (2001) shows that even all $\gamma_{i}$ are constrained between 0,1 ), as long as the tail density of $\gamma_{i}$ takes the form $c_{b}(1-\gamma)^{b}$ with $0<c_{b}<\infty . b<-\frac{1}{2}$ as $\gamma$ approaches 1 from the left. the spectral density of $\frac{1}{N} \sum_{i=1}^{N}\left(1-\gamma_{i} L\right)^{-1} u_{i t}$ becomes unbounded where $L$ denotes the lag operator. However, this condition actually requires the distribution of $\gamma_{i}$ to be heavily clustered near 1 . 
stylized facts. Therefore, we perform the simulation using the following steps:

1. Generate the log level of prefecture income using the formula: $\tilde{y}_{i t}=\mu_{i}+$ $\tilde{y}_{i, t-1}+u_{i t}^{*}$, where the drift parameter $\mu_{i}$ and the variance of i.i.d. error $u_{i t}^{*}, \sigma_{i}^{2}$, are those derived from actual prefecture data estimates.

2. Generate bond rate using the formula: $r_{t}=r_{t-1}+\tilde{u}_{t}$, where the error term $\tilde{u}_{t}$ is normally distributed with mean 0 and variances $\tilde{\sigma}_{u}^{2}$ equal to the variance from the real data.

3. MF1 and MF2 are generated according to:

$$
m_{i t}=\hat{\alpha}_{i}+\hat{\gamma}_{i} m_{i, t-1}+\hat{c}_{i} r_{t}+\hat{\beta}_{i} \tilde{y}_{i t}+\epsilon_{i t}^{*},
$$

where $m_{i t}$ denotes the log level of MF1 or MF2, $\tilde{y}_{i t}$ denotes the log level of prefecture income and $\epsilon_{i t}^{*}$ is the corresponding error term with variance equal to the one observed at the prefecture level. We use the estimated random coefficients $\left(\hat{\alpha}_{i}, \hat{\beta}_{i}, \hat{\gamma}_{i}, \hat{c}_{i}\right)$ to generate the disaggregate money demand data. The initial values for MF1 and MF2 are the prefecture level MF1 and MF2 at year 1992 .

4. Transform the prefecture log data into level data. Sum the disaggregate data to get aggregate data.

\section{6b. Results based on Simulated Aggregate Data}

The estimation results based on simulated data are very similar to what we have obtained in section 3. The lagged dependent coefficients are near 1 and the income coefficients are either insignificant or have the wrong sign. Table 17 provide the least squares estimates of the simulated M1 and M2 equation. They are of similar magnitude to those obtained from the actual data (see Table 6).

To see whether the above result is a pure chance event, we repeat the above simulation 500 times and plot the histogram for the estimated lagged dependent variable coefficients 
in Figures 6 and 7 . We also repeat the simulation by randomly assigning $\underline{\theta}_{i}$ to different prefectures income data. The results are plotted in Figures 8 and 9 . As one can see from these figures the possibility of obtaining near unit root in the aggregate data is very high. They appear to support the contention that the diametrically opposite results between the aggregate and disaggregate analysis are largely due to ignoring heterogeneity in the micro units in the aggregate analysis.

\section{Choice between Aggregate or Disaggregate Model}

Section 5 demonstrates analytically that it is possible to have stable micro relations but unstable macro relations when heterogeneity in the micro units are present. Section 6 uses simulation to show that the diametrically opposite inferences between aggregate and disaggregate analysis are possible with the features of money demand data observed in Japan. Granted that there is indeed a stable relation between money demand, income and interest rate at the prefecture level in Japan, the questions naturally arise are that shall we favor using aggregate data to predict the aggregate outcomes and study the impact of policy changes or shall we first obtain disaggregate predictions or outcomes of policy changes, then sum the disaggregate outcomes to obtain the aggregate outcomes. In this section we first compare the prediction performance, then compare the implication of policy changes using aggregate and disaggregate models.

Before we compare the prediction performance between the aggregate and disaggregate models, we note that when parameter heterogeneity is present in the disaggregate loglinear AR(1) model, Lewbel (1994) has shown that if the same log-linear form is used. the aggregate model is of $\mathrm{AR}(\infty)$. since higher order lag dependent variables are not statistically significant. we try to see if some nonlinear models would perform better than the log-linear model. We consider three alternatives: translog (Christensen, Jorgenson and Lau (1975)), Box-Cox transformation and inverse interest rate specifications. Tables 18. 19, and 20 present the respective estimates. The implied long-run income elasticity of translog model is 0.99 and interest rate elasticity is -0.1 for $M 1$ and for $M 2$ the implied 
long run income elasticity is 1.33 and the implied long run interest rate elasticity is 0.058 when the logarithm of real GDP and bond rate are at the mean value of 15.28 and 1.39 respectively. However, the interest rate elasticity for $M 2$ is of the wrong sign. The implied income and interest rate elasticities of Box-Cox transformation model using the procedure of Poirier and Melino (1978) yield practically zero income and interest elasticities. For the inverse interest rate model, the long run income elasticities is 0.75 for $M 1$ and 3.06 for $M 2$ and the long run interest rate elasticities are -1.3 for $M 1$ and -1.01 for $M 2$ for the inverse interest rate model for the full sample. For the sub sample period 1992.I-2000.IV, the inverse of bond rate coefficients are not significant and logarithm of real GDP has the wrong signs. Moreover, the lagged dependent coefficients both exceed 1. Therefore we cannot draw consistent conclusion about the long-run relations based on the inverse of interest rate for both full sample and subsample periods.

The nonlinear models not only may imply implausible income and interest rate elasticities. they also have statistically insignificant parameter estimates for the higher order terms. Moreover, neither do the nonlinear models predict better than ARIMA or log-linear model (see Table 8). Therefore, for the aggregate models we shall focus our comparison using only ARIMA or model (2.3).

In choosing between whether to predict aggregate variables using aggregate or disaggregate equations $\left(H_{d}\right)$. Grunfeld and Griliches (1960) suggest using the criterion of:

$$
\text { Choosing } H_{d} \text { if }{\underset{\sim}{d}}_{d}^{\prime} e_{d}<{\underset{\sim}{\epsilon}}_{a}^{\prime} e_{a} \text {, otherwise choosing } H_{a} \text {, }
$$

where $\underline{\sim}_{d}$ and $\underline{\epsilon}_{a}$ are the estimates of the errors in predicting aggregate outcomes under $H_{d}$ and $H_{a}$, respectively. Table 21 presents the within sample fit comparisons in the first row and the post-sample prediction comparison in the second row. Both criteria unambiguously favor predicting aggregate outcomes by summing the outcomes from the disaggregate equations. ${ }^{6}$

${ }^{6}$ This simulation results may also be viewed as numerical generalization of Pesaran's (1999) 
We next perform simulation studies to evaluate the impact of changing interest rates on the aggregate money demand using either the macro or the disaggregate equations. We shock the economy by lowering the interest rate for $50 \%$ and observe the evolution of the money demand at the prefecture level and then get aggregate money demand from the prefecture money demand. The prefecture money demand is modeled by the random coefficient model specified in (4.1). To use the macro equations to evaluate the interest rate shock impact, we assume that we have available only the aggregate data that have been constructed form the prefecture level and have no information about how the prefecture level data are generated.

We need to construct three aggregate series through simulation study. First, the "true aggregate series" before and after the interest rate shock. Again we simulate the disaggregate data using all stylized facts from the actual Japan's money demand data, and we shock the disaggregate system at period $T=101$, which gives interest rate as half of its level at $\mathrm{T}=100$.

Secondly, assume that we don't know the existence of the disaggregate equations but only have the final simulated 100 periods of aggregate data, we use these observation points to perform OLS estimation and use the estimated coefficients to evaluate the response of this aggregate system to interest rate shock and we call it "simulated aggregate response".

Finally, we construct the "simulated aggregate response from disaggregate equations" from the micro data by first estimating a random coefficients model using data of first 100 periods then using the estimated coefficients to construct prefecture level money demand after the interest rate shock, and aggregating them to obtain the estimated aggregate response.

The error sum of squares for predicting true system's responses after interest shock is much smaller for the disaggregate system as compared to aggregate system. For a typical

results that if the static disaggregate model is correctly specified, the mean-squared error of optimal aggregate forecast is larger than the corresponding mean-squared error of forecasting the aggregate based on the disaggregate model. 
simulation, the error sum of square for M1 from disaggregate system is at the magnitude of $5.88^{*} 10^{7}$, and that from aggregate system is $2.51^{*} 10^{10}$; the error sum of square for M2 for the disaggregate system is at the magnitude of $2.04 * 10^{43}$, and that from the aggregate system is $9.55^{*} 10^{45}$. As the absolute numbers of the error sum of squares are very large, we further look at the responses paths from the disaggregate and aggregate system.

Figure 10 contains the changes of both the "true aggregate series" and "simulated disaggregate responses", with the dashed line shows the simulated disaggregate responses and the solid line shows the "true aggregate responses". The top two figures are for MI and the bottom two are for M2, and the left half shows the short run responses while the right half shows the long run responses. This figure shows that the series of the "true aggregate series" and the simulated disaggregate responses are very similar. Both lines show increase of money demand in the short run and then converge to certain equilibrium level in the long run.

Figure 11 plots the responses of both the macro equations and the disaggregate equations together with the "true aggregates". Again the top two figures are for $M 1$ and the bottom two figures are for $M 2$, and the left two figures show the short run responses while the right two figures show the long run responses. The two very close lines denote "true aggregates (solid line)" and "aggregates from the disaggregate equations (dashed line)", respectively, and the third dashed line denotes "the macro equation response". These figures show that summing the micro responses to get the aggregates is close to the true ones but the macro equation responses are very different from the true ones. Because of the near unit root phenomenon in the aggregate model even though the estimated short-run interest elasticity is small, it would almost imply the presence of "liquidity trap" in the long-run.

Both the prediction comparison and policy evaluation unambiguously point out that when micro heterogeneity is present, it is better to generate the aggregate outcomes by summing the disaggregate outcomes from disaggregate equations than using the aggregate 
model to generate aggregate outcomes..

\section{Conclusions}

In this paper we study the issues of whether Japan has a stable money demand function under the low interest rate policy using both aggregate and disaggregate data. There are two notable results. First, the only agreeable information is that the interest rate coefficients although are statistically significant, they are not of the magnitude to imply the presence of liquidity trap in the short run. We have here mostly only reported findings in terms of semi-log form for the interest rate. We have tried alternative functional forms for the interest rate such as logarithmic transformation or the inverse transformation. Both specifications could imply the presence of liquidity trap if the estimated coefficients have the right magnitude. However, the alternative functional forms do not fit the data or yield post-sample prediction as well as the semi log form reported here. The panel data estimated short-run semi-interest rate elasticity based on random coefficient models is -0.048 for MF1 and -0.009 for MF2. The long-run interest elasticities are -0.139 for MF1 and -0.019 for MF2.

Second, the estimated relationships between money demand and income are diametrically opposite to each other between the aggregate and disaggregate data analysis. The estimated relationships using aggregate data are sensitive to the time period covered. Depending on the sample period used, they are either of wrong signs or statistically insignificant or yield such unbelievable magnitudes. For instance, the estimated long-run income elasticities are 75.23 for M1 and 11.04 for M2 in the 90's (see Table 4). On the other hand, the disaggregate data analysis yields stable relationships between money demand and income and are consistent with economic theory. The estimated short-run income elasticity for MF1 and MF2 are 0.88 and $0.4 \overline{7}$, respectively. The long-run income elasticity are 2.56 for MF1 and 1.01 for MF2 based on random coefficient models. These results appear to be consistent with the broad average relationship observed between M2 and income in Japan. The average growth rate for $\mathrm{M} 2$ in the 80 's is about $9.34 \%$, the inflation rate is $1.98 \%$, with 
a real M2 growth rate of $7.36 \%$. The real growth rate of GDP during this period is $4.13 \%$. Had interest rate stayed constant, the ratio of these two numbers, 1.78, gives a measure of long-run income elasticity of the demand for real M2. In the 90's, the average growth rate of M2 is $2.69 \%$, the inflation rate is $0.14 \%$. The real growth rate of M2 is about $2.55 \%$. The real GDP growth rate during this period is $1.38 \%$. The ratio of real growth rate of M2 and real GDP is about 1.85. Taking account of the fact that 1.78 or 1.85 is the average measure assuming interest rate stayed constant, while in fact the five year bond rate had fallen from 9.332 at $1980 . I$ to 5.767 at $1989 . I V$ and further to 1.289 at $2000 . I V$ and the estimated impact of interest rate changes on money demand, these figures are indeed very close to the estimated long-run income elasticities based on disaggregate data analysis.

We have also tried to explore the source of the seemingly contradictory evidence between the aggregate and disaggregate data. It appears that the lack of stable relationship between aggregate money demand and income could be due to the lack of sample variability in the aggregate data. But more importantly, our analytical and simulation results appear to suggest that it is the ignoring of heterogeneity in the micro units and the effect of nonlinear aggregation that lead to this seemingly contradictory evidence. In other words, our empirical analysis appears to suggest that more attention should be directed at the issues of aggregation and more structure is needed to justify aggregate data models. The results show that it is possible to have stable micro relations but unstable macro relations. It is also better to sum the outcomes from the micro equations to get the aggregates in predicting the aggregate outcomes or evaluating the impact of policy changes rather than relying on aggregate variables to generate aggregate outcomes. To the extent that economic theory is valuable for giving structure to individual behavior, it should be applied at the individual level only. A generalization of sophisticated individual behavior to the aggregate behavior under the guise of representative agent can lead to seriously misleading aggregate model. 


\section{Appendix A: Definitions of Disaggregate Data}

This appendix explains the definitions of prefecture income statistics, population and the prefecture money aggregates.

1. Prefecture income statistics

Prefecture income statistics complied by the Economic and Social Research Institute (Former Economic Planning Agency of Japan) for each fiscal year provide a good counter part to national GDP. We download the data from the home page of Economic and Social Research Institute from 1987 - 1997, and supplement the data of 1986 - 1997 from Fujiki and Mulligan (1996).

The prefecture income data is deflated by the gross prefecture expenditure deflator during the period from fiscal year 1985 to fiscal year 1997.

2. Population

We use population to convert prefecture data to per capita data. The population of each prefecture is as of the beginning of October of each year.

Prefecture Money Aggregates

1. $\mathrm{MF} 1$

MF1 is the end of month outstanding demand deposits held by individuals and firms at domestically licensed bank. MF1 data by prefecture are available from Monthly Economic Statistics of Bank of Japan. Due to the extension of the coverage banks included in this statistics in April 1989 and occasional consolidations of banks. MF1 data sometimes show an unusual increase, particularly in April 1989.

MF1 is the prefecture counter part of national M1. However, the following caveats are in order. First, MF1 data do not include cash. because regional data on the 
amount of currency held by individuals are not available. Second, they do not have the breakdown by the individuals and firms. Third, they do not include the demand deposit at the community banks, the Norinchukin bank, and the Shokochukin bank, which are included in the computation of the M1 statistics. However, MF1 data always explain about 70 percent of M1 during 1985 - 1998, and about 80 percent from 1989 - 1991, and about 70 percent from 1992 to 1997. Therefore, MF1 predicts about 70 percent of M1 for $1991-1997$, the period covered in the disaggregate time series analysis.

\section{MF2}

MF2 is the sum of the deposit in domestically licensed banks, community banks and Shokochukin Bank. MF2 consists of both demand deposit and savings deposit and is our counterpart of national M2 + CD minus cash, with the existence of the following statistical discrepancies:

First, the prefecture breakdown of CDs outstanding does not exist, hence we ignore them. Second, we only eliminate the deposit held by the financial institutions for domestically licensed banks, since the breakdown of deposits held by financial institutions by prefecture are available for domestically licensed banks only. Third, we exclude the data for the Norinchukin bank from the regional deposit statistics to avoid possible double count of same deposits. However, MF2 data always explain about 98 percent of $\mathrm{M} 2+\mathrm{CD}$ from $1985-1998$, about 95 percent from 1993 - 1995, and about 90 percent from 1996 - 1997. Therefore, MF2 predicts almost constant proportion of M2 $+\mathrm{CD}$ when we are careful about the selection of sample period.

Both MF1 and MF2 figures are deflated by the gross prefecture expenditure deflator and divided by the population in each region to obtain per-capita real money balance. 
Appendix B: Hierarchical Bayes Estimation of Random

Coefficients and Mixed Fixed and Random Coefficients Models

In this appendix we explain how the random coefficient models and the mixed fixed and random coefficients models are estimated in the Bayesian framework. We start with a general framework by Hsiao, et.al (1993), and then explain how this general framework is implemented in this paper.

Suppose there are observations of $1+k_{1}+k_{2}$ variables $\left(y_{i t}, x_{i t}^{\prime}, z_{i t}^{\prime}\right)$ of $N$ cross-sectional units over $T$ time periods, where $i=1, \ldots, N$ and $t=1, \ldots, T$.

Denote

$$
\begin{aligned}
& \underset{\tilde{N} T}{y}=\left(\begin{array}{c}
y_{1} \\
\vdots \\
y_{N}
\end{array}\right)
\end{aligned}
$$

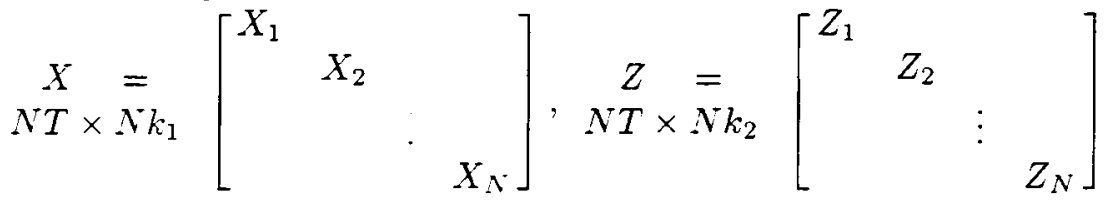

where

$$
\begin{aligned}
& \tilde{I}_{i}^{y_{i}^{\prime} \times T}=\left(y_{i 1}, \ldots, y_{i T}\right),
\end{aligned}
$$

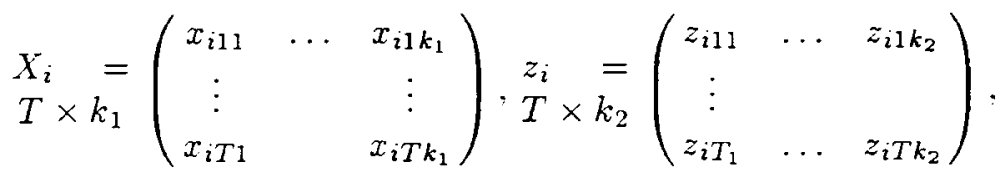

$$
\begin{aligned}
& i=1, \ldots, N \text {. }
\end{aligned}
$$

We assume that

$$
\underset{\sim}{y}=X \underset{\sim}{\beta}+Z_{\underline{\gamma}}+\underset{\sim}{u}
$$

where $\underset{\sim}{\beta}$ and 2 are $N k_{1} \times 1$ and $N k_{2} \times 1$ vectors respectively, and

$$
\stackrel{u}{\sim} \times 1=\left(\begin{array}{c}
\stackrel{u}{1}_{1} \\
\vdots \\
\underline{u}_{N}
\end{array}\right) \sim N\left(0, \sum\right),
$$




$$
\underline{u}_{i}^{\prime}=\left(u_{i 1}, \ldots, u_{i T}\right), E\left({\underset{\sim}{u}}_{i} u_{j}^{\prime}\right)=\left\{\begin{array}{cll}
\sigma_{i}^{2} I_{T} & \text { if } & i=j \\
0 & \text { if } & i \neq j
\end{array}\right.
$$

We further assume that the $N k_{1} \times 1$ vector $\beta_{\sim}$ satisfies:

$$
\underset{\sim}{\beta}=\left[\begin{array}{c}
\underline{\beta}_{-1} \\
\vdots \\
\underset{\sim}{\beta}
\end{array}\right]=A_{1} \underline{\sim}+\underline{\underline{\beta}}
$$

where $\underset{\sim}{\beta}$ is $k_{1} \times 1$ vector, $i=1, \ldots, N, A_{1}$ is an $N k_{1} \times m$ matrix with known elements, $\bar{\beta}$ is an $m \times 1$ vector of constants, and

$$
\eta \sim N(0, C), \underset{\sim}{\eta}=\left[\begin{array}{c}
\eta_{1} \\
\vdots \\
\eta_{N}
\end{array}\right]
$$

and the variance covariance matrix $C$ is assumed to be nonsingular, and $E\left(\eta_{i}\right)=0, E\left(\eta_{i} \eta_{j}^{\prime}\right)=$ $\left\{\begin{array}{lll}\Delta & \text { if } & i=j \\ 0 & \text { if } & i \neq j\end{array}\right.$.

The $N k_{2} \times 1$ vector of $\gamma$ is assumed to satisfy

$$
\gamma=\left(\begin{array}{c}
\underline{\gamma}_{1} \\
\vdots \\
\underline{\gamma}_{N}
\end{array}\right)=A_{2} \bar{\gamma}_{N},
$$

where $A_{2}$ is an $N k_{2} \times n$ matrix with known elements, and $\bar{\gamma}$ is an $n \times 1$ vector of constants. Because $A_{2}$ is as known matrix, (B.1) is formally identical to

$$
\underline{\underline{y}}=X \underset{\sim}{3}+\tilde{Z}_{\tilde{\gamma}}+\underline{u}
$$

where $\tilde{Z}=Z A_{2}$. However, by postulating (B.4) we can allow for various possible fixed parameter configurations.

B.1. Formulation and estimation of dynamic random coefficient models.

If we let

$$
\begin{aligned}
& Z=0, \quad A_{1}=e_{N} \otimes I_{K} \\
& C=I_{N} \otimes \Delta .
\end{aligned}
$$

in (B.1), where $e_{N}$ denotes the $N \times 1$ vector of ones, we get random coefficients model with

$$
\underset{\sim}{\beta}=\bar{\sim}+\eta_{i}
$$




$$
\underline{\sim}_{i}=Q_{i} \bar{\beta}+\underset{\sim}{v_{i}}, \quad i=1, \ldots, N
$$

where $Q_{i}=\left({\underset{\sim}{i,-1}}_{i}, X_{i}\right), \underset{\sim}{\beta}$ includes the coefficient for lagged dependent variable

$$
\underline{\sim}_{i,-1}=\left(y_{i 0}, \ldots, y_{i, T-1}\right)^{\prime}, \text { and }{\underset{\sim}{v}}_{i}=Q_{i} \underline{\sim}_{i}+{\underset{\sim}{i}}_{i}
$$

We change notation $X_{i}$ to $Q_{i}=\left(y_{i,-1}, X_{i}\right)$ to emphasize that the present model is a dynamic one, where $X_{i}$ denotes all the exogenous explanatory variables. As a result of the dynamic feature of the present model, $E\left(\nu_{\sim} \mid Q_{i}\right) \neq 0$ (Hsiao (2001b)). Therefore, contrary to the static case, the least squares estimator of the common mean, $\bar{\theta}$ is inconsistent. In addition, the covariance matrix of $\nu_{i}, V$, is not easily derivable, hence the procedure of premultiplying (B.8) by $V^{-1 / 2}$ to transform the model into one with serially uncorrelated error is not implementable. Teither the Instrumental Variable method appears implementable as the instruments that are uncorrelated with $\underset{\sim}{\nu_{i}}$ are most likely uncorrelated with $Q_{i}$ as well.

Our estimation procedures use the Hierarchical Bayes Estimator developed by Hsiao, Pesaran and Tahmiscioglu (1999).

This estimator is performed in the following steps:

Step 1: Under the assumption that $y_{i 0}$ are fixed and known and $\eta_{i}$ and $u_{i t}$ are independently normally distributed, we can implement the Bayes estimator of $\overline{3}$ conditional on $\sigma_{i}^{2}$ and $\Delta$ using the formula for the (unconditional) posterior distribution of $\underset{\sim}{3}$ given $\underset{\sim}{y}$ (Hsiao et.al (1993, p.i0)).

The Bayes Estimator conditional on $\Delta$ and $\sigma_{i}^{2}$ is:

$$
\stackrel{\overline{\overline{3}}}{\sim}_{-B}=\left\{\sum_{i=1}^{N}\left(\sigma_{i}^{2}\left(Q_{i}^{\prime} Q_{i}\right)^{-1}+\Delta\right)^{-1}\right\}^{-1} \sum_{i=1}\left[\sigma_{i}^{2}\left(Q_{i}^{\prime} Q_{i}\right)^{-1}+\Delta\right]^{-1} \hat{\sim}_{i} .
$$

Since in practice, $\sigma_{i}^{2}$ and $\Delta$ are rarely known. we substitute the consistent estimates for 
$\sigma_{i}^{2}$ and $\Delta:$

$$
\begin{aligned}
\hat{\sigma}_{i}^{2} & =\frac{\hat{u}_{i}^{\prime} \hat{\sim}_{i}}{T-K}=\frac{1}{T-K} y_{\sim}^{\prime}\left[I-Q_{i}\left(Q_{i}^{\prime} Q_{i}\right)^{-1} X_{i}^{\prime}\right] y_{i}, \\
\hat{\Delta} & =\frac{1}{N} \sum_{i=1}^{N}\left(\hat{\sim}_{\sim}-\frac{1}{N} \sum_{i=1}^{N} \hat{\beta}_{\sim}\right)\left(\hat{\beta}_{\sim}-\frac{1}{N} \sum_{i=1}^{N} \hat{\beta}_{\sim}\right)^{\prime}, \\
\hat{\sim}_{i} & =\left(Q_{i}^{\prime} Q_{i}\right)^{-1} Q_{i}^{\prime}{\underset{\sim}{i}}_{i}
\end{aligned}
$$

The above steps give empirical Bayes Estimator. We save the estimated $\underset{\sim}{\bar{\beta}}$ and the related variances to construct the informative prior for the Hierarchical Bayes Estimator.

Step 2: Use Gibbs Sampler to Calculate the Hierarchical Bayes Estimator.

Assume that the prior distribution of $\sigma_{i}^{2}$ and $\Delta$ are independent and are distributed as

$$
P\left(\Delta^{-1}, \sigma_{1}^{2}, \ldots, \sigma_{N}^{2}\right)=W\left(\Delta^{-1} \mid(\rho R)^{-1}, \rho\right) \Pi_{i=1}^{N} \sigma_{i}^{-1},
$$

where $W$ represents the Wishart distribution with scale matrix $\rho R$ and degrees of freedom ( $\rho$ ) (Lindley and Smith (1972)). Incorporating this prior into (B.7) and (B.8), we use Gibbs sampler to calculate marginal post error densities of the parameters of interest by integrating out $\sigma_{i}^{2}$ and $\Delta$ from the joint posterior density.

The Gibbs sample is an iterative Markov Chain Monte Carlo method which only requires the knowledge of the full conditional densities of the parameter vector (e.g. Gelfand and Smith (1990)). Starting from some arbitrary initial values, say $\left(\theta_{1}^{(0)}, \theta_{2}^{(0)}, \ldots, \theta_{k}^{(0)}\right)$ for a parameter vector $\underset{\sim}{\theta}=\left({\underset{\sim}{1}}_{1}, \ldots,{\underset{\sim}{k}}_{k}\right)$, it samples alternatively from the conditional density of each component of the parameter vector conditional on the values of other components sampled in the latest iteration. That is:

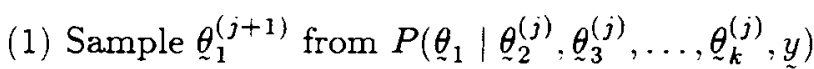

(2) Sample ${\underset{\sim}{2}}_{2}^{(j+1)}$ from $P(\underline{\theta}_{2} \mid{\underset{\sim}{1}}_{1}^{(j+1)}, \underline{\theta}_{3}^{(j)}, \ldots, \underbrace{(j)}_{k}, y)$

(k) Sample ${\underset{\sim}{k}}^{(j+1)}$ from $P\left({\underset{\sim}{*}}_{k} \mid{\underset{\sim}{1}}^{(j+1)}, \ldots,{\underset{\sim}{k-1}}_{(j+1)}^{y+y}\right)$

The vectors ${\underset{\sim}{(0)}}^{\theta_{\sim}^{(1)}}, \ldots, \stackrel{\sim}{(k)}^{(k)}$ forms a Markov Chain with transition probability from 
stage $\underline{\theta}^{(j)}$ to the next stage ${\underset{\theta}{(j+1)}}^{(j) i n g}$

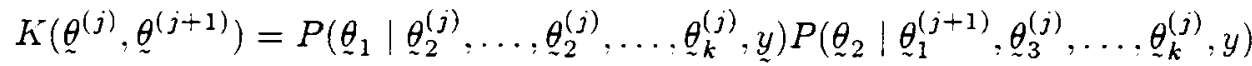

$$
\begin{aligned}
& \ldots P\left({\underset{\sim}{*}}_{k} \mid{\underset{\sim}{\theta}}_{1}^{(j+1)}, \ldots,{\underset{\sim}{k-1}}_{(j+1)}^{y} \underset{\sim}{y}\right)
\end{aligned}
$$

As the number of iterations $j$ approaches infinity, the sample values in effect can be regarded as drawing from true joint and marginal posterior densities. Moreover, the ergodic averages of functions of the sample values will be consistent estimation of their expected values.

In our case, $\underset{\sim}{\theta_{i}}$ is $\underset{\sim}{\beta}$. Under the assumption that the prior of $\underset{\sim}{\bar{\beta}}, \underset{\sim}{\beta^{*}}$, and the related variances $\Psi$ are obtained from Empirical Bayes Estimator, the Gibbs sampler for (B.6) (B.7) are easily obtained from

$$
\begin{aligned}
& P\left(\underset{\sim}{\beta} \mid \underset{\sim}{y}, \underset{\sim}{\bar{\beta}}, \Delta^{-1}, \sigma_{1}^{2}, \ldots, \sigma_{N}^{2}\right) \sim N\left\{A_{i}\left(\sigma_{i}^{-2} Q_{i}^{\prime}{\underset{\sim}{i}}_{i}+\Delta^{-1} \underset{\sim}{\beta}\right), A_{i}\right\}
\end{aligned}
$$

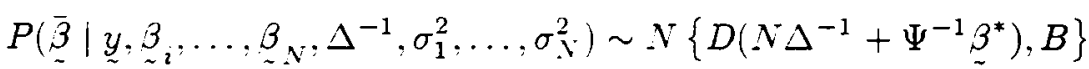

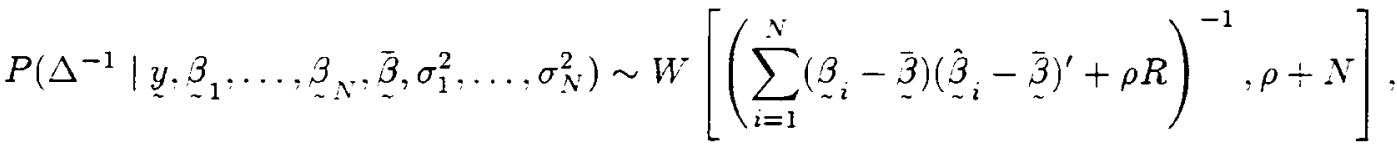

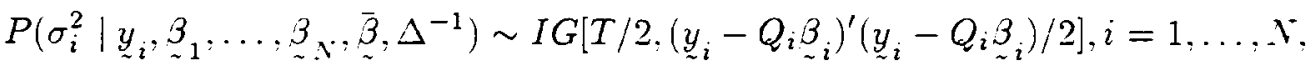

where $A_{i}=\left(\left(\sigma_{i}^{-2} Q_{i}^{\prime} Q_{i}+\Delta^{-1}\right)^{-1}, D=\left(N \Delta^{-1}+\Psi^{-1}\right)^{-1}, \underset{\sim}{\hat{3}}=\frac{1}{N} \sum_{i=1}^{N} \beta_{i}\right.$, and $I G$ denotes the inverse gamma distribution.

2. Mixed Fixed and Random Coefficient Models.

(B.3) and (B.1') gives the mixed fixed and random coefficient model used by Hsiao et.al, (1989) and Hsiao and Tahmiscioglu (1997).

The estimator could have followed the Bayesian estimators by Hsiao et.al (1993). However, as diffuse priors are assumed for $\underset{\sim}{\overline{3}}$ in this framework, while Gibbs samples works under informative priors (using diffuse prior fails to converge to the right distribution (Hobert and Casella (1996)). We therefore base our estimation on the random coefficient 
model above, but change the priors for the individual specific effects to 10 for MF1 and MF2, and save the estimated coefficients as the mixed fixed and random estimation results.

We performed 11.000 iterations for the Gibbs sampler and throw away the first 1,000 iterations to make sure that our results approximates the performance of the estimators under limiting distributions. 


\section{References}

Akaike, H., (1973). "Information Theory and an Extension of the Maximum Likelihood Principle." in Proc. 2nd int. Symp. Information Theory, ed. by B.M. Petrov and F. Csaki, 267-281, Budapest: Akademiai Kiado.

Anderson, T.W., (2001). "Reduced Rank Regression in Cointegrated Models," Journal of Econometrics, (forthcoming).

Bernanke, B.S. (2001), "Japanese Monetary Policy: A Case of Self Induced Paralysis?" in Ryoichi Mikitaui and A.S. Posen, Eds., Japan's Financial Crisis and its Parallels to U.S. Experience, Institute for International Economics, Bank of Japan.

Bohn, H.. (1995). "The Substitutability of Budget Deficits in a Stochastic Economy," Journal of Money, Credit and Banking, 27, 257-271.

Box, G.E.P. and D.R. Cox (1964). "An Analysis of Transformations," Journal of the Royal Statistical Society. Series B, 26, 211-252.

Box, G.E.P. and G.M. Jenkins (1970). Time Series Analysis, Forecasting and Control. San Francisco: Holden Day.

Brewer, K.R.W. (1973), "Some Consequences of Temporal Aggregation and Systematic Sampling for ARIMA and ARMAX Models," Journal of Econometrics, 1, 133-154.

Christensen, L., D.W. Jorgenson and L.J. Lau (1975). "Transcendental Logarithmic Utility Functions" American Economic Review, 65, 367-83.

Dickey. D.A. and W.A. Fuller (1979). "Distribution of the Estimators for Autoregressive Time Series with a Unit Root." Journal of the American Statistical Association, 74, $427-431$.

. (1981). "Likelihood Ratio Statistics for Autoregressive Time Series with a Unit Root," Econometrica, 49, 1057-1072.

Doi, T., (2000). "Wagakuni ni okera Kokurai no Jizokukanousei to Zaiser Unei," in Ihori et al. "Zaisei Akazino Keiza; Bunsehi; Cyu-cyokiteki Shiten karano Kousatsu," Keizaibunseki Seisaku kenkyu no Shiten Series, vol. 16, 9-15.

Forni, M. and M. Lippi (1997). Aggregation and the Microfoundations of Dynamic Macroeconomics, Oxford: Oxford Lniversity Press.

(1999). "Aggregation of Linear Dynamic Microeconomics Models," Journal of Mathematical Economics, 31, 131-158.

Friedman, M. and A.J. Schwartz, (1991). "Alterative Approaches to Analyzing Economic Data." American Economic Review, 81. 39-49.

Fujiki, H., (2001). "Money Demand Near Zero Interest Rate: Evidence from Regional Data." mimeo.

C. Hsiao and Y. Shen (2002). "Is there a Stable Money Demand Function Under the Low Interest Rate Policy? - A Panel Data Analysis," Monetary and 
Economic Studies, Bank of Japan, (forthcoming).

K. Okina, and S. Shiratsuke (2001). "Monetary Policy Under Zero Interest Rate: Viewpoints of Central Bank Economists," Monetary and Economic Studies, 19, $\mathrm{s}-1,89-130$.

Gelfand, A.E. and A.F.M. Smith (1990). "Sampling-Based Approaches to Calculating Marginal Densities," 85, 398-409.

Granger, C.W.J. (1980). "Long Memory Relationships and the Aggregation of Dynamic Models," Journal of Econometrics, 14, 227-238.

Grunfeld, Y. and Z. Griliches (1960). "Is Aggregation Necessarily Bad?," Review of Economics and Statistics, 42, 1-13.

Hausman, J.A., (1978). "Specification Tests in Econometrics," Econometrica, 46, 1251-71.

Hobert, J.P., Casella, G. (1996). "The Effect of Improper Priors On Gibbs Sampling in Hierarchical Linear Mixed Models," Journal of the American Statistical Association, 91, 1461-1473.

Hsiao, C., (1986). Analysis of Panel Data, Econometric Society monographs No. 11, New York: Cambridge University Press.

(1997a). "Cointegration and Dynamic Simultaneous Equations Models," Econometrica, 65, 647-670.

, (1997b). "Statistical Properties of the Two Stage Least Squares Estimator Under Cointegration," Review of Economic Studies, 64, 385-398.

, (2001a). "Identification and Dichotomization of Long- and Short-Run Relations of Cointegrated Vector Autoregressive Models," Econometric Theory, 17, 889912.

, (2001b). "Economic Panel Data Methodology," in International Encyclopedia of the Social and Behavioral Sciences, ed. by N.J. Snelser and P.B. Bates, Oxford: Elsevier. (forthcoming).

and A.K. Tahmiscioglu (1997). "A Panel Analysis of Liquidity Constraints and Firm Investment," Journal of the American Statistical Association, 92, 45う-465.

M.H. Pesaran and A.K. Tahmiscioglu (1999). "Bayes Estimation of ShortRun Coefficients in Dynamic Panel Data Models," in Analysis of Panels and Limited Dependent Variables Models, ed. by C. Hsiao, L.F. Lee, K. Lahiri and M.H. Pesaran, Cambridge: Cambridge University Press, 268-296.

and S. Wang (2002). "Estimation of Structural Vector Autoregressive Integrated Process," mimeo.

Johansen, S., (1988). "Statistical Analysis of Cointegration Vectors," Journal of Economic Dynamics and Control, 12, 231-254.

(1991). "Estimation and Hypothesis Testing of Cointegration Vectors in Gaussian Vector Autoregressive Models," Econometrica, 59, 1551-1580. 
Klein. L.R. (1953). A Textbook of Econometrics, Evanston: Row Peterson and Company.

Laidler, D.E.W., (1969). The Demand for Money: Theories and Evidence, Scranton, Penn: International Textbook Company.

Lewbel, A. (1992). "Aggregation with Log-Linear Models," Review of Economic Studies, $59,635-642$. $\overline{84,905-918 .}$

(1994). "Aggregation and Simple Dynamics," American Economic Review,

Lindley, D.V. and A.F.M. Smith (1972). "Bayes Estimates for the Linear Model," Journal of the Royal Statistical Society, B. 34, 1-41.

Nakashima, K., and M. Saito (2000). "Strong Money Demand and Nominal Rigidity: Evidence from the Japanese Money Market Under the Low Interest Rate Policy," mimeo.

Nerlove, M., (1958). The Dynamics of Supply: Estimation of Farmers' Response to Price," Baltimore, the John Hopkins Press.

Pesaran, M.H. (1999). "On Aggregation of Linear Dynamic Models," mimeo. and Smith (1995). "Estimation of Long-Run Relationships from Dynamic Heterogeneous Panels," Journal of Econometrics, 68, 79-114.

R.G. Pierse and M.S. Kumar (1989), "Econometric Analysis of Aggregation in the Context of Linear Prediction Models", Journal of Econometrics 57, 861-888.

Poirier, D.J. and A. Melino (1978). "A Note on the Interpretation of Regression Coefficients Within a Class of Truncated Distributions," Econometrica, 46, 1207-1209.

Schwarz, G. (1978). "Estimating the Dimension of a Model," Annals of Statistics, 6, $461-464$.

Stoker, T.M. (1984). "Completeness, Distribution Restrictions, and the Form of Aggregate Functions," Econometrica, 52, 887-907.

(1993). "Empirical Approaches to the Problem of Aggregation Over Individuals," Journal of Economic Literature, 31, 1827-1874.

Theil. H. (1954). Linear Aggregation of Economic Relations. Amsterdam: North Holland.

Tiao G.C., (1972). "Asymptotic Behavior of Temporal Aggregates of Time Series." Biometrika. $59,525-531$.

Trivedi. P.K. (1985). "Distributed Lags, Aggregation and Compounding: Some Econometric Implications," Review of Economic Studies, 52, 19-35.

Zellner, A. (1996). "Models, Prior Information and Bayesian Analysis," Journal of Econometrics, $75,51-68$. 
Table 1 ADF Tests of Unit Roots ${ }^{a, b}$

\begin{tabular}{|c|c|c|c|c|c|c|c|c|c|}
\hline \multirow{2}{*}{$\begin{array}{l}\text { Sample } \\
\text { Period }\end{array}$} & \multirow{2}{*}{$\begin{array}{l}\text { Lagged } \\
\text { difference } \\
\text { order }\end{array}$} & \multicolumn{2}{|c|}{ Real GDP } & \multicolumn{2}{|c|}{ Real M2 } & \multicolumn{2}{|c|}{ Real Ml } & \multicolumn{2}{|c|}{ Bond Rate } \\
\hline & & $\overline{\mathrm{ADF}}$ & $\overline{\text { SBC }}$ & ADF & $\widehat{\text { SBC }}$ & $\overline{\mathrm{ADF}}$ & $\overline{\text { SBC }}$ & $\overline{\mathrm{ADF}}$ & $\overline{\text { SBC }}$ \\
\hline (1980.IV & 0 & -2.59 & $-9.3298^{*}$ & -3.33 & -9.442 & 4.03 & -8.5996 & -0.95 & $-1.29^{*}$ \\
\hline . & 1 & -2.76 & -9.2884 & -2.31 & -9.882 & 1.76 & $-8.7956^{*}$ & -0.87 & -1.24 \\
\hline \multirow[t]{4}{*}{ 2000.IV) } & 2 & -2.87 & -9.2435 & -2.24 & $-9.898^{*}$ & 1.66 & -8.7414 & -0.78 & -1.21 \\
\hline & 3 & -2.21 & -9.3273 & -2.19 & -9.831 & 1.78 & -8.6796 & -0.89 & -1.15 \\
\hline & 4 & -1.76 & -9.2902 & -1.64 & -9.796 & 1.41 & -8.6301 & -0.86 & -1.08 \\
\hline & 5 & -1.71 & -9.2903 & -3.33 & -9.759 & 1.10 & -8.5667 & -0.90 & -1.01 \\
\hline (1992.I & 0 & -0.86 & -8.957 & 3.85 & -10.48 & 2.39 & -8.731 & -2.17 & $-1.58^{*}$ \\
\hline - & 1 & -0.69 & -8.9218 & 2.03 & $-10.49^{*}$ & 0.51 & $-9.057^{*}$ & -2.15 & -1.48 \\
\hline \multirow[t]{3}{*}{ 2000.IV) } & 2 & -0.45 & $-8.9594^{*}$ & 1.09 & -10.475 & 0.56 & -8.96 & -2.31 & -1.43 \\
\hline & 3 & -0.49 & -8.8735 & 1.39 & -10.411 & 0.78 & -8.878 & -2.60 & -1.42 \\
\hline & 4 & -0.48 & -8.7777 & 0.63 & -10.385 & 0.52 & -8.78 & -2.84 & -1.37 \\
\hline
\end{tabular}

a The * indicates the optimally selected lag order.

b The $95 \%$ critical values are -2.897 and -2.95 for the $1980 . I V-2000 . I V$ and 1992.I -2000 .IV periods respectively. 
Table 2 Johansen Likelihood Ratio Test Results When M1 (M2), GDP and Bond Rate are I(1)

\begin{tabular}{|c|c|c|c|c|c|c|c|}
\hline $\begin{array}{l}\text { Sample } \\
\text { Period }\end{array}$ & Hypothesis & $\begin{array}{l}\text { Lag } \\
\text { Order } \\
\text { Selection }\end{array}$ & $\begin{array}{l}\text { Information } \\
\text { Criterion }\end{array}$ & $\begin{array}{r}\text { Likelihood } \\
\text { Ratio }\end{array}$ & $\begin{array}{r}5 \% \\
\text { critical } \\
\text { value } \\
\end{array}$ & $\begin{array}{r}1 \% \\
\text { critical } \\
\text { value } \\
\end{array}$ & Conclusion \\
\hline \multirow{9}{*}{$\begin{array}{l}\text { 1980.IV- } \\
2000 . I V\end{array}$} & $\mathrm{Ml}, \mathrm{r}=0$ & \multirow[t]{3}{*}{1} & \multirow[t]{3}{*}{ SBC } & 62.44008 & 34.91 & 41.07 & \multirow{3}{*}{ Cointegration } \\
\hline & $\mathrm{M} 1, \mathrm{r}<=1$ & & & 21.50105 & 19.96 & 24.60 & \\
\hline & \multirow[t]{4}{*}{$\mathrm{Ml}, \mathrm{K}=2$} & & & 2.678774 & 9.24 & 12.97 & \\
\hline & & \multirow[t]{3}{*}{2} & \multirow[t]{3}{*}{$\overline{\mathrm{AIC}}$} & 63.36653 & 34.91 & 41.07 & \multirow{3}{*}{$\begin{array}{l}\text { One } \\
\text { Cointegration }\end{array}$} \\
\hline & & & & 22.18303 & 19.96 & 24.60 & \\
\hline & & & & 2.393634 & 9.24 & 12.97 & \\
\hline & $\mathrm{M} 2, \mathrm{r}=0$ & \multirow[t]{3}{*}{2} & \multirow[t]{3}{*}{$\mathrm{SBC}(\mathrm{AIC})$} & 54.55278 & 34.91 & 41.07 & \multirow{3}{*}{$\begin{array}{l}\text { One } \\
\text { Cointegration }\end{array}$} \\
\hline & $\mathrm{M} 2, \mathrm{~K}<=1$ & & & 21.48478 & 19.96 & 24.60 & \\
\hline & $\mathrm{M} 2, \mathrm{r}<=2$ & & & 5.156355 & 9.24 & 12.97 & \\
\hline \multirow{9}{*}{$\begin{array}{l}1992 . \mathrm{I}- \\
2000 . \mathrm{IV}\end{array}$} & $\mathrm{Ml},=0$ & \multirow[t]{3}{*}{1} & \multirow[t]{3}{*}{ SBC (AIC) } & 33.29918 & 34.91 & 41.07 & \multirow{3}{*}{$\begin{array}{l}\text { No } \\
\text { Cointegration }\end{array}$} \\
\hline & $\mathrm{M} 1, \mathrm{r}<=1$ & & & 12.60056 & 19.96 & 24.60 & \\
\hline & $\mathrm{M} 1, \mathrm{r}<=2$ & & & 4.643863 & 9.24 & 12.97 & \\
\hline & $\mathrm{M} 2, \mathrm{I}=0$ & \multirow[t]{3}{*}{1} & \multirow[t]{3}{*}{ SBC } & 39.44755 & 34.91 & 41.07 & \multirow{3}{*}{$\begin{array}{l}\text { One } \\
\text { Cointegration }\end{array}$} \\
\hline & $\mathrm{M} 2, \mathrm{r}<=1$ & & & 16.55820 & 19.96 & 24.60 & \\
\hline & \multirow[t]{4}{*}{$\mathrm{M} 2, \mathrm{r}<=2$} & & & 4.706671 & 9.24 & 12.97 & \\
\hline & & \multirow[t]{3}{*}{2} & \multirow[t]{3}{*}{ AIC } & 35.24054 & 34.91 & 41.07 & \multirow{3}{*}{$\begin{array}{l}\text { One } \\
\text { Cointegrarion }\end{array}$} \\
\hline & & & & 16.12073 & 19.96 & 24.60 & \\
\hline & & & & 4.100181 & 9.24 & 12.97 & \\
\hline
\end{tabular}


Table 3 Johansen (1991) Normalized Cointegration Vector *

\begin{tabular}{|c|c|c|c|c|}
\hline & \multicolumn{2}{|c|}{ 1980.IV-2000.IV } & \multicolumn{2}{|c|}{ 1992.I - 2000.IV } \\
\hline & M1 & $\mathrm{M} 2$ & M1 & M2 \\
\hline $\begin{array}{l}\text { Based on } \\
\text { SBC }\end{array}$ & & & & \\
\hline $\begin{array}{c}\text { GDP } \\
\text { Bond Rate } \\
\text { Intercept }\end{array}$ & $\begin{array}{c}-0.72 \\
(-1.337) \\
-0.13 \\
(0.079) \\
-26.43 \\
(21.22) \\
\end{array}$ & $\begin{array}{c}3.83 \\
(3.34) \\
0.108 \\
(0.17) \\
-44.29 \\
(53.54) \\
\end{array}$ & $\begin{array}{c}75.23 \\
(258) \\
2.666 \\
(9.92) \\
-1156 \\
(4017) \\
\end{array}$ & $\begin{array}{c}8.225 \\
(8.27) \\
0.316 \\
(0.41) \\
-112.7 \\
(129.3) \\
\end{array}$ \\
\hline $\begin{array}{c}\text { Based on } \\
\text { AIC }\end{array}$ & & & & \\
\hline $\begin{array}{c}\text { GDP } \\
\text { Bond Rate } \\
\text { Intercept }\end{array}$ & $\begin{array}{c}0.183 \\
(0.674) \\
-0.05 \\
(0.049) \\
-17.62 \\
(10.59) \\
\end{array}$ & $\begin{array}{c}\text { Same as } \\
\text { SBC }\end{array}$ & $\begin{array}{l}\text { Same as } \\
\text { SBC }\end{array}$ & $\begin{array}{c}11.036 \\
(12.33) \\
0.404 \\
(0.552) \\
-156.4 \\
(192.4)\end{array}$ \\
\hline
\end{tabular}

* Standard Error in parentheses. 
Table 4 Anderson's (2001) Reduced Rank Estimation

\begin{tabular}{c|c|c}
\hline $\begin{array}{c}\text { Sample } \\
\text { Period }\end{array}$ & $\begin{array}{c}\text { Monetary } \\
\text { Aggregates }\end{array}$ & The Long Run Coefficient $\Pi$ \\
\hline 1980.I V-2000.IV & M1 & {$\left[\begin{array}{lll}-0.0004 & -0.0002 & 0.0645 \\
-0.0010 & -0.0006 & 0.1523 \\
-0.3178 & -0.1775 & 48.0654\end{array}\right]$} \\
& M2 & {$\left[\begin{array}{ccc}-0.0007 & -0.0004 & 0.0645 \\
-0.0013 & -0.0008 & 0.1195 \\
-0.5535 & -0.3415 & 49.697\end{array}\right]$} \\
\hline 1992.I-2000.IV & M1 & {$\left[\begin{array}{lll}0.0026 & 0.0004 & 0.0376 \\
0.0193 & 0.0031 & 0.2741 \\
2.1893 & 0.3468 & 31.1393\end{array}\right]$} \\
& \multirow{2}{*}{ M2 } & {$\left[\begin{array}{lll}0.0000 & 0.0000 & 0.0378 \\
-0.0001 & -0.0001 & 0.1061 \\
-0.0348 & -0.015631 .3812\end{array}\right]$} \\
\hline
\end{tabular}

${ }^{*} \Pi$ is the long run coefficient matrix in

$$
\begin{aligned}
& {\left[\begin{array}{c}
\Delta \ln \left(R G D P_{t}\right) \\
\Delta \ln \left(M_{2, t}\right) \\
\Delta r_{t}
\end{array}\right]=\left[\begin{array}{l}
c_{1} \\
c_{2} \\
c_{3}
\end{array}\right]+\left[\begin{array}{lll}
\pi_{11} & \pi_{12} & \pi_{13} \\
\pi_{21} & \pi_{22} & \pi_{23} \\
\pi_{31} & \pi_{32} & \pi_{33}
\end{array}\right]\left[\begin{array}{c}
\ln \left(R G D P_{t-1}\right) \\
\ln \left(M_{2, t-1}\right) \\
r_{t-1}
\end{array}\right]} \\
& +\sum_{p=1}^{P}\left[\begin{array}{lll}
B_{11 p} & B_{12 p} & B_{13 p} \\
B_{21 p} & B_{22 p} & B_{23 p} \\
B_{31 p} & B_{32 p} & B_{33 p}
\end{array}\right]\left[\begin{array}{c}
\Delta \ln \left(R G D P_{t-p}\right) \\
\Delta \ln \left(M_{2 t-p}\right) \\
\Delta r_{t-p}
\end{array}\right]+\left[\begin{array}{l}
u_{1 t} \\
u_{2 t} \\
u_{3 t}
\end{array}\right]
\end{aligned}
$$


Table 5 Unrestricted Error Correction Estimation When M1(M2), GDP and Bond Rate Are I(1)*

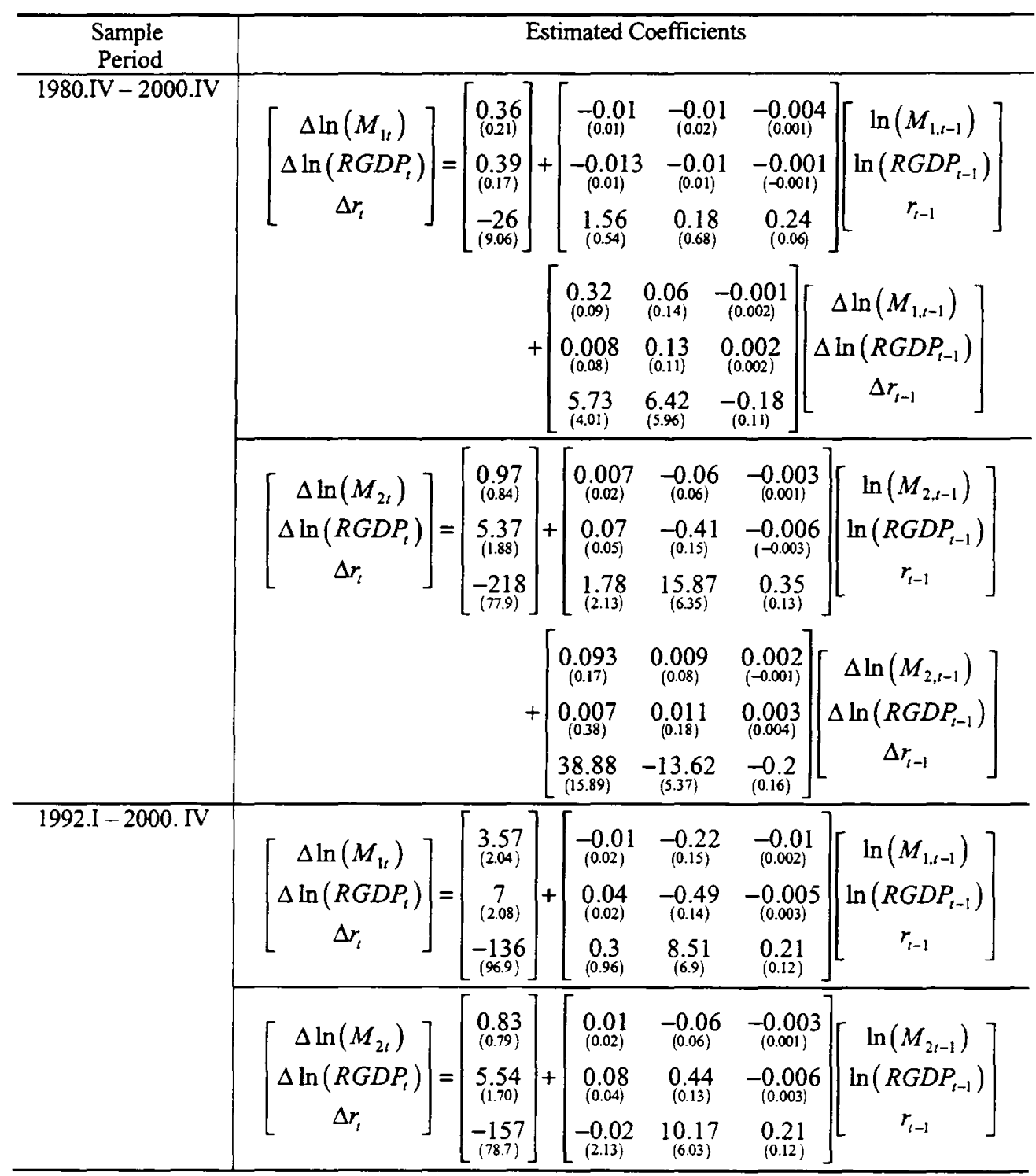


Table 6 Least Squares Estimation of Money Demand

\begin{tabular}{|c|c|c|c|c|}
\hline Dependent Variable & $\begin{array}{l}\text { Sample } \\
\text { Period } \\
\end{array}$ & Variable & $\begin{array}{c}\text { Parameter } \\
\text { Estimate }\end{array}$ & $\begin{array}{r}\text { Standard } \\
\text { Error }\end{array}$ \\
\hline \multirow[t]{8}{*}{ M2 } & $1980 . \mathrm{IV}$ & Intercept & 1.30462 & 0.28975 \\
\hline & - & Real GDP & -0.15425 & 0.04538 \\
\hline & 2000.IV & $\mathrm{RM} 2(-1)$ & 1.07022 & 0.02790 \\
\hline & & Bond Rate & -0.00186 & 0.00069 \\
\hline & 1992.I & Intercept & -0.16272 & 0.85081 \\
\hline & & Real GDP & 0.00847 & 0.06772 \\
\hline & 2000.IV & RM2(-1) & 1.00295 & 0.02248 \\
\hline & & Bond Rate & -0.00250 & 0.00140 \\
\hline \multirow[t]{8}{*}{ M1 } & 1980.IV & Intercept & 0.46907 & 0.21852 \\
\hline & - & Real GDP & -0.01857 & 0.01700 \\
\hline & 2000.IV & $\operatorname{RMl}(-1)$ & 0.98964 & 0.01249 \\
\hline & & Bond Rate & -0.00566 & 0.00135 \\
\hline & 1992.I & Intercept & -0.68783 & 2.10228 \\
\hline & - & Real GDP & 0.08414 & 0.14898 \\
\hline & 2000.IV & $\mathrm{RMl}(-1)$ & 0.96038 & 0.01999 \\
\hline & & Bond Rate & -0.01005 & 0.00283 \\
\hline
\end{tabular}


Table 7 ARIMA Modeling of M2 and M1*

\begin{tabular}{|c|c|c|}
\hline $\begin{array}{c}\text { Sample } \\
\text { Period }\end{array}$ & $\begin{array}{l}\text { Dependent } \\
\text { variable }\end{array}$ & Estimated equation \\
\hline \multirow[t]{2}{*}{$\begin{array}{l}1980 . \mathrm{V}- \\
2000 . \mathrm{V}\end{array}$} & $\Delta m_{1 t}$ & $\Delta m_{1 t}=\underset{(3.52)}{0.01155+0.56 \Delta m_{1 t-1}+e_{t}}$ \\
\hline & $\Delta m_{2 t}$ & $\Delta m_{2 t}=\underset{(3.66)}{0.01}+\underset{(4.59)}{0.5 \Delta m_{2 t-1}}+\underset{(2.26)}{0.246 \Delta m_{2 t-2}}+e_{t}$ \\
\hline \multirow[t]{2}{*}{$\begin{array}{l}1992 . \mathrm{I}- \\
2000 . \mathrm{IV}\end{array}$} & $\Delta m_{1}$ & $\Delta m_{1 t}=\underset{(1.94)}{0.0042+0.558 \Delta m_{1 t-1}+e_{t}}$ \\
\hline & $\Delta m_{2 z}$ & $\Delta m_{2 t}=\underset{(-1.49)}{-0.007}+\underset{(3.28)}{0.517 \Delta m_{2 t-1}}+\underset{(3.00)}{0.479} \Delta m_{2 t-2}+e_{t}$ \\
\hline
\end{tabular}

* Model selection based on SBC. 
Table 8 Root Mean Square Error Comparison For One-Period-ahead Forecasting

\begin{tabular}{|c|c|c|c|c|}
\hline $\begin{array}{l}\text { Dependent } \\
\text { Variable }\end{array}$ & & Model & $\begin{array}{c}\text { RMSE }^{* *} \\
1998 . \mathrm{I}-2000 . \mathrm{IV}\end{array}$ & $\begin{array}{c}\text { RMSE }^{* *} \\
1998 . I I I-2000 . I V\end{array}$ \\
\hline $\mathrm{Ml}$ & 1 & $\begin{array}{l}\text { ARIMA }(1,1,0) \\
\text { OLS } \\
\text { Unrestricted ECM } \\
\quad \text { with bond rate } \\
\text { Two Stage } \\
\text { Least Squares } \\
\text { OLS with inverse bond } \\
\text { rate } \\
\text { Translog Estimation }\end{array}$ & $\begin{array}{r}0.0109^{*} \\
0.012 \\
0.018 \\
0.015 \\
0.012 \\
0.22\end{array}$ & $\begin{array}{r}0.011^{*} \\
0.019 \\
0.012 \\
0.015 \\
0.016 \\
-\ldots\end{array}$ \\
\hline M2 & 1 & $\begin{array}{l}\text { ARIMA }(2,1,0) \\
\text { OLS } \\
\text { Unrestricted ECM } \\
\text { with bond rate } \\
\text { Two Stage } \\
\text { Least Squares } \\
\text { OLS with inverse bond } \\
\text { rate } \\
\text { Translog Estimation }\end{array}$ & $\begin{array}{r}0.009^{*} \\
0.011 \\
0.011 \\
0.014 \\
0.017 \\
0.09\end{array}$ & $\begin{array}{r}0.004^{*} \\
0.0047 \\
0.007 \\
0.006 \\
0.0056 \\
-\#\end{array}$ \\
\hline
\end{tabular}

* : Smallest Root Mean Square Error.

** : The RMSE for the 1998.I - 2000.IV column is calculated by estimation using data from 1980.I to 1997.IV and predict 1998.I to 2000.IV; the RMSE for the 1998.III -2000.IV column is calculated by estimation using data from 1991.III to 1998.II and predict 1998.III to 2000.IV.

$\# \quad$ : Cannot be calculated due to multicollinearity. 
Table 9 Hierarchical Bayes Estimated Random Coefficients

\begin{tabular}{l|r|r|rr}
\hline & \multicolumn{2}{|c|}{ 47 Prefectures } & \multicolumn{2}{c}{ 40 Prefectures } \\
\hline Variables & Coefficients & $\begin{array}{r}\text { Standard } \\
\text { Deviation }\end{array}$ & Coefficients & $\begin{array}{r}\text { Standard } \\
\text { Deviation }\end{array}$ \\
\hline MF1(-1) & 0.6507019 & 0.0316268 & 0.6555294 & 0.0344682 \\
Income & 0.927945 & 0.1090934 & 0.8812118 & 0.1137414 \\
Bond Rate & -0.05055 & 0.006016 & -0.047598 & 0.0061865 \\
Constant & -2.272464 & 0.3708626 & -2.125453 & 0.382336 \\
\hline & & & & \\
MF2(-1) & 0.5248475 & 0.06054 & 0.5337534 & 0.0689148 \\
Income & 0.4776609 & 0.0563903 & 0.4725214 & 0.0642067 \\
Bond Rate & -0.009717 & 0.0032794 & -0.008941 & 0.0034183 \\
Constant & 0.0604931 & 0.2244695 & 0.0425582 & 0.2396531 \\
\hline
\end{tabular}

Variance Covariance matrix of thetai for MF1(40 Prefectures):

$$
\left[\begin{array}{cccc}
0.015 & -0.001 & 0.0017 & -0.024 \\
-0.001 & 0.177 & 0.059 & -0.588 \\
0.0017 & -0.059 & 0.0005 & -0.023 \\
-0.024 & -0.588 & -0.023 & 2.017
\end{array}\right]
$$

Variance Covariance matrix of thetai for MF2(40 Prefectures):

$$
\left[\begin{array}{cccc}
0.068 & -0.031 & 0.0023 & -0.13 \\
-0.031 & 0.062 & 0.0003 & -0.107 \\
0.0023 & 0.0003 & 0.0014 & -0.009 \\
-0.13 & -0.107 & -0.009 & 0.8385
\end{array}\right]
$$


Table 10 Hierarchical Bayes Estimated Mixed Fixed and Random Coefficients

\begin{tabular}{l|r|r|rr}
\hline & \multicolumn{2}{|c|}{ 47 Prefectures } & \multicolumn{2}{c}{40 Prefectures } \\
\hline Variables & Coefficients & $\begin{array}{r}\text { Standard } \\
\text { Deviation }\end{array}$ & Coefficients & $\begin{array}{r}\text { Standard } \\
\text { Deviation }\end{array}$ \\
\hline MF1(-1) & 0.6389765 & 0.0409127 & 0.6533347 & 0.0339363 \\
Income & 0.2988121 & 0.0848417 & 0.8809016 & 0.1154574 \\
Bond Rate & -0.071933 & 0.007101 & -0.048035 & 0.0062235 \\
Constant & -0.116582 & 0.2817165 & -2.119956 & 0.3889621 \\
\hline & & & & \\
MF2(-1) & 0.4770931 & 0.0579894 & 0.5378975 & 0.0689838 \\
Income & 0.4318347 & 0.0565629 & 0.4742547 & 0.0631223 \\
Bond Rate & -0.013406 & 0.0028535 & -0.008728 & 0.0034719 \\
Constant & 0.3876087 & 0.192636 & 0.0223581 & 0.2436108 \\
\hline
\end{tabular}

Variance Covariance matrix of thetai for MF1 (40 Prefectures):

$$
\left[\begin{array}{cccc}
0.014 & -0.001 & 0.0017 & -0.024 \\
-0.001 & 0.176 & 0.058 & -0.584 \\
0.0017 & 0.058 & 0.0005 & -0.022 \\
-0.024 & -0.584 & -0.022 & 2.000
\end{array}\right]
$$

Variance Covariance matrix of thetai for MF2 (47Prefectures):

$$
\left[\begin{array}{cccc}
0.069 & -0.032 & 0.0024 & -0.13 \\
-0.032 & 0.063 & 0.0003 & -0.107 \\
0.0024 & 0.0003 & 0.0015 & -0.009 \\
-0.13 & -0.107 & -0.009 & 0.8448
\end{array}\right]
$$


Table 11 Hausman Specification Test of Measurement Error*

\begin{tabular}{ccc}
\hline Variables & RE Models & FE Models \\
\hline MF1 & $24.68^{\wedge}$ & 45.92 \\
MF2 & $84.17^{M}$ & -- \\
\hline
\end{tabular}

* Since we use Gibbs sampler to estimate the random coefficients models and the mixed fixed and random effects models, the calculated Hausman statistic can be slightly different for different simulations.

^: Deleting Bond rate to avoid singularity problem

$M$ : Dropping constant to avoid singularity problem.

--: Hausman Test statistics is negative. 
Table 12 Fixed Effects (FE) and Random Effects (RE) Estimation

\begin{tabular}{|c|c|c|c|c|c|}
\hline & & \multicolumn{2}{|c|}{ Fixed Effects } & \multicolumn{2}{|c|}{ Random Effects } \\
\hline & Variables & Coefficients & t-value & Coefficients & $t$-value \\
\hline \multirow[t]{2}{*}{$\begin{array}{l}40 \\
\text { Prefectures }\end{array}$} & $\begin{array}{l}\text { M1F }(-1) \\
\text { Income } \\
\text { Bond rate } \\
\text { Constant }\end{array}$ & $\begin{array}{l}0.7223413 \\
0.6500417 \\
-0.035468\end{array}$ & $\begin{array}{l}30.418895 \\
8.9506568 \\
-7.502673\end{array}$ & $\begin{array}{l}0.6958649 \\
0.7945655 \\
-0.045742 \\
-1.915043\end{array}$ & $\begin{array}{l}25.69604 \\
10.378702 \\
-9.398455 \\
-0.2925\end{array}$ \\
\hline & $\begin{array}{l}\text { M2F (-1) } \\
\text { Income } \\
\text { Bond rate } \\
\text { Constant }\end{array}$ & $\begin{array}{l}0.6526298 \\
0.2571169 \\
-0.00954\end{array}$ & $\begin{array}{l}14.061279 \\
5.2103729 \\
-3.320842\end{array}$ & $\begin{array}{c}0.4982692 \\
0.3673084 \\
-0.014314 \\
0.5143107\end{array}$ & $\begin{array}{l}11.419157 \\
7.3975925 \\
-5.290189 \\
0.2486889\end{array}$ \\
\hline
\end{tabular}


Table 13 Income Elasticity and Semi-Interest Rate Elasticity Based On Random Coefficient and Mixed Models

\begin{tabular}{l|l|ll|ll}
\hline \multirow{2}{*}{$\begin{array}{l}\text { Elasticities } \\
\text { of Interest }\end{array}$} & & \multicolumn{2}{|l|}{ MF1 } & \multicolumn{2}{l}{ MF2 } \\
\cline { 3 - 6 } & & Short Run & Long Run & Short Run L Long Run \\
\hline $\begin{array}{l}\text { Income } \\
\text { Elasticity }\end{array}$ & $\begin{array}{l}\text { Random } \\
\text { Coefficients }\end{array}$ & 0.881 & 2.56 & 0.473 & 1.01 \\
\cline { 2 - 6 } & $\begin{array}{l}\text { Mixed } \\
\text { Models }\end{array}$ & 0.881 & 2.54 & 0.474 & 1.03 \\
\hline $\begin{array}{l}\text { Semi-interest } \\
\text { Elasticity }\end{array}$ & $\begin{array}{l}\text { Random } \\
\text { Coefficients }\end{array}$ & -0.0475 & -0.0138 & -0.0089 & -0.019 \\
\cline { 2 - 6 } & $\begin{array}{l}\text { Mixed } \\
\text { Models }\end{array}$ & -0.048 & -0.0139 & -0.0087 & -0.0189 \\
\hline
\end{tabular}


Table 14 Two Stage Least Squares Estimation For M1 and M2

\begin{tabular}{|c|c|c|c|c|c|}
\hline $\begin{array}{l}\text { Dependent } \\
\text { Variable }\end{array}$ & $\begin{array}{l}\text { Sample } \\
\text { Period }\end{array}$ & Variable & $\begin{array}{c}\text { Parameter } \\
\text { Estimate }\end{array}$ & $\begin{array}{r}\text { Standard } \\
\text { Erro } \\
\end{array}$ & $t$ value \\
\hline \multirow[t]{2}{*}{ M1 } & $\begin{array}{c}1980 . \mathrm{IV} \\
- \\
2000 . \mathrm{IV}\end{array}$ & $\begin{array}{l}\text { Intercept } \\
\text { M1(-1) } \\
\text { M1(-2) } \\
\text { GDP(-1) } \\
\text { Bond Rate } \\
\end{array}$ & $\begin{array}{r}0.375692 \\
1.319778 \\
-0.32958 \\
-0.01374 \\
-0.00402 \\
\end{array}$ & $\begin{array}{l}0.207400 \\
0.093789 \\
0.093070 \\
0.016063 \\
0.001347 \\
\end{array}$ & $\begin{array}{r}1.81 \\
14.07 \\
-3.54 \\
-0.86 \\
-2.99 \\
\end{array}$ \\
\hline & $\begin{array}{c}1992.1 \\
- \\
2000 . I V\end{array}$ & $\begin{array}{l}\text { Intercept } \\
\text { Ml(-1) } \\
\text { Ml(-2) } \\
\text { GDP(-1) } \\
\text { Bond Rate }\end{array}$ & $\begin{array}{l}4.311913 \\
1.489444 \\
-0.49015 \\
-0.27628 \\
-0.01024 \\
\end{array}$ & $\begin{array}{l}3.230759 \\
0.166541 \\
0.156715 \\
0.231358 \\
0.003025 \\
\end{array}$ & $\begin{array}{r}1.33 \\
8.94 \\
-3.13 \\
-1.19 \\
-3.39 \\
\end{array}$ \\
\hline \multirow[t]{2}{*}{ M2 } & $\begin{array}{c}\text { 1980.IV } \\
- \\
2000 . \mathrm{IV}\end{array}$ & $\begin{array}{l}\text { Intercept } \\
\text { M2(-1) } \\
\text { M2(-2) } \\
\text { GDP(-1) } \\
\text { Bond Rate } \\
\end{array}$ & $\begin{array}{l}0.931084 \\
1.502049 \\
-0.45290 \\
-0.10920 \\
-0.00147 \\
\end{array}$ & $\begin{array}{l}0.332153 \\
0.087207 \\
0.098063 \\
0.050970 \\
0.000604 \\
\end{array}$ & $\begin{array}{r}2.80 \\
17.22 \\
-4.62 \\
-2.14 \\
-2.44 \\
\end{array}$ \\
\hline & $\begin{array}{c}1992 . I \\
- \\
2000 . \mathrm{IV}\end{array}$ & $\begin{array}{l}\text { Intercept } \\
\text { M2(-1) } \\
\text { M2(-2) } \\
\text { GDP(-1) } \\
\text { Bond Rate }\end{array}$ & $\begin{array}{l}-0.10242 \\
1.208455 \\
-0.20761 \\
0.006507 \\
-0.00202\end{array}$ & $\begin{array}{l}1.140174 \\
0.174600 \\
0.173027 \\
0.094242 \\
0.001584\end{array}$ & $\begin{array}{r}-0.09 \\
6.92 \\
-1.20 \\
0.07 \\
-1.28\end{array}$ \\
\hline
\end{tabular}


Table 15 Least Squares Estimation of Money Demand M1 (M2)-Currency

\begin{tabular}{c|ccrrr}
\hline $\begin{array}{c}\text { Dependent } \\
\text { Variable }\end{array}$ & $\begin{array}{c}\text { Sample } \\
\text { Period }\end{array}$ & Variable & $\begin{array}{r}\text { Parameter } \\
\text { Estimate }\end{array}$ & $\begin{array}{r}\text { Standard } \\
\text { Error }\end{array}$ & t value \\
\hline \multirow{3}{*}{ M1 } & $1980 . I V$ & Intercept & 0.40465 & 0.27360 & 1.48 \\
& - & Real GDP & -0.01656 & 0.01870 & -0.89 \\
& $2000 . I V$ & M1(-1) & 0.99184 & 0.01379 & 71.93 \\
& & Bond Rate & -0.00561 & 0.00168 & -3.34 \\
\cline { 2 - 6 } & $1992 . I$ & Intercept & -0.13807 & 2.55447 & -0.05 \\
& - & Real GDP & 0.04922 & 0.17968 & 0.27 \\
& $2000 . I V$ & M1(-1) & 0.95927 & 0.02226 & 43.09 \\
& & Bond Rate & -0.01217 & 0.00335 & -3.63 \\
\hline \multirow{4}{*}{ M2 } & & & & & \\
& & Intercept & 1.42314 & 0.30912 & 4.60 \\
& $1980 . I V$ & Real GDP & -0.17217 & 0.04797 & -3.59 \\
& - & M2(-1) & 1.08074 & 0.02928 & 36.91 \\
& $2000 . I V$ & Bond Rate & -0.00182 & 0.00069043 & -2.64 \\
\hline & & Intercept & -0.05223 & 0.86170 & -0.06 \\
& $1992 . I$ & Real GDP & -0.00191 & 0.06930 & -0.03 \\
& - & M2(-1) & 1.00613 & 0.02477 & 40.62 \\
& $2000 . I V$ & Bond Rate & -0.00246 & 0.00143 & -1.72 \\
\hline & & & &
\end{tabular}


Table 16 Two Stage Least Squares Estimation For M1 (M2)-Currency

\begin{tabular}{|c|c|c|c|c|c|}
\hline $\begin{array}{l}\text { Dependent } \\
\text { variable }\end{array}$ & $\begin{array}{l}\text { Sample } \\
\text { Period }\end{array}$ & Variable & $\begin{array}{c}\text { Parameter } \\
\text { Estimate }\end{array}$ & $\begin{array}{r}\text { Standard } \\
\text { Error }\end{array}$ & $t$ value \\
\hline \multirow[t]{2}{*}{ Ml } & $\begin{array}{c}\text { 1980.IV } \\
- \\
2000 . \mathrm{IV}\end{array}$ & $\begin{array}{l}\text { Intercept } \\
\text { Ml(-1) } \\
\text { Ml(-2) } \\
\text { GDP(-1) } \\
\text { Bond Rate }\end{array}$ & $\begin{array}{r}0.309286 \\
1.374958 \\
-0.38457 \\
-0.00991 \\
-0.00368 \\
\end{array}$ & $\begin{array}{l}0.252302 \\
0.094940 \\
0.094469 \\
0.017254 \\
0.001609\end{array}$ & $\begin{array}{r}1.23 \\
14.48 \\
-4.07 \\
-0.57 \\
-2.28 \\
\end{array}$ \\
\hline & $\begin{array}{c}1992 . \mathrm{I} \\
- \\
2000 . \mathrm{IV}\end{array}$ & $\begin{array}{l}\text { Intercept } \\
\text { M1(-1) } \\
\text { Ml(-2) } \\
\text { GDP(-1) } \\
\text { Bond Rate }\end{array}$ & $\begin{array}{r}4.861598 \\
1.588392 \\
-0.59165 \\
-0.30954 \\
-0.01120\end{array}$ & $\begin{array}{l}3.520021 \\
0.151125 \\
0.141427 \\
0.249802 \\
0.003227\end{array}$ & $\begin{array}{r}1.38 \\
10.51 \\
-4.18 \\
-1.24 \\
-3.47\end{array}$ \\
\hline \multirow[t]{2}{*}{$\mathrm{M} 2$} & $\begin{array}{c}1980 . \mathrm{IV} \\
- \\
2000 . \mathrm{IV}\end{array}$ & $\begin{array}{l}\text { Intercept } \\
\text { M2(-1) } \\
\text { M2(-2) } \\
\text { GDP(-1) } \\
\text { Bond Rate }\end{array}$ & $\begin{array}{r}0.963669 \\
1.511705 \\
-0.45983 \\
-0.11382 \\
-0.00146 \\
\end{array}$ & $\begin{array}{l}0.367020 \\
0.087687 \\
0.100682 \\
0.055842 \\
0.000612 \\
\end{array}$ & $\begin{array}{r}2.63 \\
17.24 \\
-4.57 \\
-2.04 \\
-2.39 \\
\end{array}$ \\
\hline & $\begin{array}{c}1992 . \mathrm{I} \\
- \\
2000 . \mathrm{IV}\end{array}$ & $\begin{array}{l}\text { Intercept } \\
\text { M2(-1) } \\
\text { M2(-2) } \\
\text { GDP(-1) } \\
\text { Bond Rate }\end{array}$ & $\begin{array}{c}-0.27114 \\
1.246219 \\
-0.24918 \\
0.021131 \\
-0.00159\end{array}$ & $\begin{array}{l}1.131228 \\
0.174734 \\
0.173719 \\
0.094927 \\
0.001623\end{array}$ & $\begin{array}{r}-0.24 \\
7.13 \\
-1.43 \\
0.22 \\
-0.98\end{array}$ \\
\hline
\end{tabular}


Table 17 Least Squares Estimation for the Simulated M1 and M2

\begin{tabular}{c|crr}
\hline $\begin{array}{c}\text { Dependent } \\
\text { Variable }\end{array}$ & Variable & $\begin{array}{c}\text { Parameter } \\
\text { Estimate }\end{array}$ & t value \\
\hline M1 & M1(-1) & 0.987828 & 63.027525 \\
& Real GDP & 0.149237 & 0.855213 \\
& Bond Rate & -0.003981 & -1.269199 \\
& Constant & -0.944954 & -0.787662 \\
\hline M2 & M2(-1) & 0.987361 & 1375.615056 \\
& Real GDP & -0.970071 & -5.734554 \\
& Bond Rate & -0.061830 & -12.879337 \\
& Constant & 13.093577 & 11.257642 \\
\hline
\end{tabular}


Table 18 Translog Estimation for the Aggregate Data ${ }^{a . b}$

\begin{tabular}{c|clrrr}
\hline Dependent Variable & $\begin{array}{c}\text { Sample } \\
\text { Period }\end{array}$ & Variable & $\begin{array}{r}\text { Parameter } \\
\text { Estimate }\end{array}$ & $\begin{array}{r}\text { Standard } \\
\text { Error }\end{array}$ & t-value \\
\hline M1 & $1980 . I V$ & Intercept & -250.56100 & 224.94780 & -1.11 \\
& - & Real GDP & 33.10157 & 28.83521 & 1.15 \\
& $2000 . I V$ & Bond Rate & 5.90375 & 6.66412 & 0.89 \\
& & GDP*GDP & -1.03097 & 0.92418 & -1.12 \\
& & Rate*Rate & 0.18397 & 0.04541 & 4.05 \\
& & GDP*Rate & -0.42975 & 0.42740 & -1.01 \\
& & & & & -2.90 \\
& $1980 . I V$ & Intercept & -290.60145 & 100.07668 & 3.05 \\
& - & Real GDP & 39.15582 & 12.82845 & -1.56 \\
& $2000 . I V$ & Bond Rate & -4.61941 & 2.96479 & -3.04 \\
& & GDP*GDP & -1.25104 & 0.41116 & 6.61 \\
& & Rate*Rate & 0.13351 & 0.02020 & 1.45 \\
& & GDP*Rate & 0.27601 & 0.19015 & \\
\hline
\end{tabular}

a Translog estimation is performed for the static money demand function only.

$b \quad$ The sub period 1992.I - 2000.IV aggregate money demand functions cannot be estimated by the static translog functions due to multicollinearity. 
Table 19 Box-Cox Transformation for the Aggregate Data

\begin{tabular}{|c|c|c|c|c|c|}
\hline $\begin{array}{l}\text { Dependent } \\
\text { Variable }\end{array}$ & $\begin{array}{l}\text { Explanatory } \\
\text { Variable }\end{array}$ & $\begin{array}{l}\text { Transformation } \\
\text { Parameter }\end{array}$ & $\begin{array}{l}\text { Coefficient } \\
\text { Estimates }\end{array}$ & $\begin{array}{c}\text { Chi } \\
\text { Square }\end{array}$ & $\begin{array}{c}\mathrm{P} \text { Value } \\
\mathrm{Pr}>\mathrm{Chi} \\
\text { square }\end{array}$ \\
\hline Case 1: & \multicolumn{5}{|c|}{ Transform left hand side only } \\
\hline MI & $\begin{array}{r}\text { Real GDP } \\
\text { Bond Rate } \\
\text { Constant }\end{array}$ & $\begin{array}{r}-2.17 \\
\\
\end{array}$ & $\begin{array}{r}1.72 \mathrm{e}-20 \\
-1.93 \mathrm{e}-15 \\
.459831 \\
\end{array}$ & $\begin{array}{r}143.481 \\
53.748\end{array}$ & $\begin{array}{l}0.000 \\
0.000\end{array}$ \\
\hline M2 & $\begin{array}{r}\text { Real GDP } \\
\text { Bond Rate } \\
\text { Constant } \\
\end{array}$ & $\begin{array}{r}0.45 \\
. \\
. \\
\end{array}$ & $\begin{array}{r}.0003714 \\
-4.751773 \\
676.9516 \\
\end{array}$ & $\begin{array}{r}220.094 \\
1.801\end{array}$ & $\begin{array}{l}0.000 \\
0.180\end{array}$ \\
\hline Case 2: & \multicolumn{5}{|c|}{ Transform left hand side and right hand side with different parameters } \\
\hline M1 & $\begin{array}{r}\text { Real GDP } \\
\text { Bond Rate } \\
\text { Constant } \\
\end{array}$ & $\begin{array}{l}-0.74 \\
-1.55 \\
-1.55\end{array}$ & $\begin{array}{r}.0000321 \\
-1.49 \mathrm{e}-10 \\
0.6437668\end{array}$ & $\begin{array}{r}146.847 \\
70.601\end{array}$ & $\begin{array}{l}0.000 \\
0.000\end{array}$ \\
\hline M2 & $\begin{array}{r}\text { Real GDP } \\
\text { Bond Rate } \\
\text { Constant } \\
\end{array}$ & $\begin{array}{l}-1.45 \\
-0.27 \\
-0.27\end{array}$ & $\begin{array}{r}9.23 e+07 \\
-.0030717 \\
-6.35 e+07 \\
\end{array}$ & $\begin{array}{r}284.779 \\
24.428\end{array}$ & $\begin{array}{l}0.000 \\
0.000\end{array}$ \\
\hline Case 3: & \multicolumn{5}{|c|}{$\begin{array}{r}\text { Transform left hand side and right hand side with different parameters, but do not } \\
\text { transform bond rate }\end{array}$} \\
\hline Ml & $\begin{array}{r}\text { Real GDP } \\
\text { Bond Rate } \\
\text { Constant }\end{array}$ & $\begin{array}{r}2.87 \\
-1.67 \\
.\end{array}$ & $\begin{array}{r}6.94 \mathrm{e}-30 \\
-2.29 \mathrm{e}-12 \\
.5979897 \\
\end{array}$ & $\begin{array}{r}140.403 \\
42.544\end{array}$ & $\begin{array}{l}0.000 \\
0.000\end{array}$ \\
\hline M2 & $\begin{array}{r}\text { Real GDP } \\
\text { Bond Rate } \\
\text { Constant }\end{array}$ & $\begin{array}{r}-1.4 \\
-0.64\end{array}$ & $\begin{array}{r}170979.4 \\
-2.57 e-07 \\
-122015.2\end{array}$ & $\begin{array}{r}264.486 \\
2.507\end{array}$ & $\begin{array}{l}0.000 \\
0.113\end{array}$ \\
\hline
\end{tabular}


Table 20 Estimating Money Demand Using the Inverse of Bond Rate

\begin{tabular}{|c|c|c|c|c|c|}
\hline Dependent Variable & $\begin{array}{l}\text { Sample } \\
\text { Period }\end{array}$ & Variable & $\begin{array}{r}\text { Parameter } \\
\text { Estimate }\end{array}$ & $\begin{array}{r}\text { Standard } \\
\text { Error }\end{array}$ & t-value \\
\hline \multirow[t]{2}{*}{ Ml } & $\begin{array}{c}1980 . \mathrm{IV} \\
- \\
2000 . \mathrm{IV}\end{array}$ & $\begin{array}{c}\text { Intercept } \\
\text { RMI(-1) } \\
\text { Real GDP } \\
\text { Inv(BondRate) }\end{array}$ & $\begin{array}{l}0.17062 \\
0.92301 \\
0.05828 \\
0.10325 \\
\end{array}$ & $\begin{array}{l}0.16659 \\
0.02362 \\
0.02167 \\
0.02238 \\
\end{array}$ & $\begin{array}{r}1.02 \\
39.08 \\
2.69 \\
4.61 \\
\end{array}$ \\
\hline & $\begin{array}{c}1992 . I \\
- \\
2000 . I V\end{array}$ & $\begin{array}{c}\text { Intercept } \\
\text { RM1(-1) } \\
\text { Real GDP } \\
\text { Inv(BondRate) }\end{array}$ & $\begin{array}{r}-2.32939 \\
0.93073 \\
0.21403 \\
0.07074 \\
\end{array}$ & $\begin{array}{l}2.10248 \\
0.02551 \\
0.14709 \\
0.02701 \\
\end{array}$ & $\begin{array}{r}-1.11 \\
36.49 \\
1.46 \\
2.62 \\
\end{array}$ \\
\hline \multirow[t]{2}{*}{ M2 } & $\begin{array}{c}1980 . \mathrm{IV} \\
- \\
2000 . \mathrm{IV}\end{array}$ & $\begin{array}{c}\text { Intercept } \\
\text { RM2(-1) } \\
\text { Real GDP } \\
\text { Inv(BondRate) }\end{array}$ & $\begin{array}{r}1.05001 \\
1.06804 \\
-0.13612 \\
0.00705 \\
\end{array}$ & $\begin{array}{l}0.28429 \\
0.03015 \\
0.04779 \\
0.00653 \\
\end{array}$ & $\begin{array}{r}3.69 \\
35.42 \\
-2.85 \\
1.08 \\
\end{array}$ \\
\hline & $\begin{array}{c}1992 . I \\
- \\
2000 . I V\end{array}$ & $\begin{array}{c}\text { Intercept } \\
\text { RM2(-1) } \\
\text { Real GDP } \\
\text { Inv(BondRate) }\end{array}$ & $\begin{array}{r}-1.17412 \\
1.00222 \\
0.07420 \\
0.00306\end{array}$ & $\begin{array}{l}0.94521 \\
0.02851 \\
0.06569 \\
0.01326\end{array}$ & $\begin{array}{r}-1.24 \\
35.16 \\
1.13 \\
0.23 \\
\end{array}$ \\
\hline
\end{tabular}


Table 21 Error Sum of Square (ESS) and Predicted Error Sum of Squares (PES) for Disaggregate and Aggregate Data

\begin{tabular}{c|cc|cc}
\hline & \multicolumn{2}{|c|}{ M1 } & \multicolumn{2}{c}{ M2 } \\
\hline & $\begin{array}{c}\text { Aggregate } \\
\text { Data }\end{array}$ & $\begin{array}{c}\text { Disaggregate } \\
\text { Data }\end{array}$ & $\begin{array}{c}\text { Aggregate } \\
\text { Data }\end{array}$ & $\begin{array}{c}\text { Disaggregate } \\
\text { Data }\end{array}$ \\
\hline ESS & $3.78 \times 10^{9}$ & $1.35 \times 10^{6}$ & $3.59 \times 10^{43}$ & $7.45 \times 10^{42}$ \\
\hline PES & $2.51 \times 10^{10}$ & $5.75 \times 10^{7}$ & $9.55 \times 10^{45}$ & $2.04 \times 10^{43}$ \\
\hline
\end{tabular}


Figure 1 Plotting Real M2 for 47 Prefectures

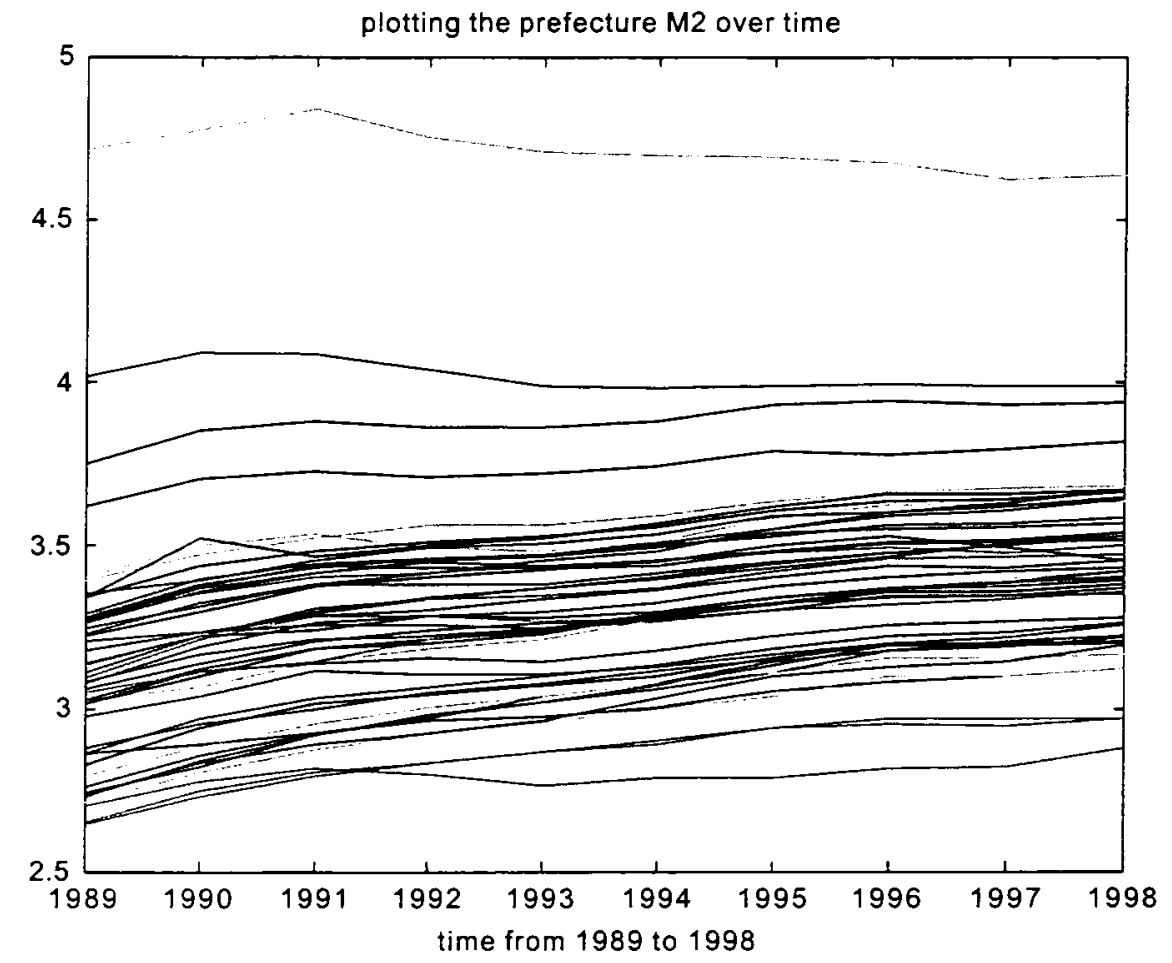


Figure 2 Plotting Real M1 For 47 Prefectures

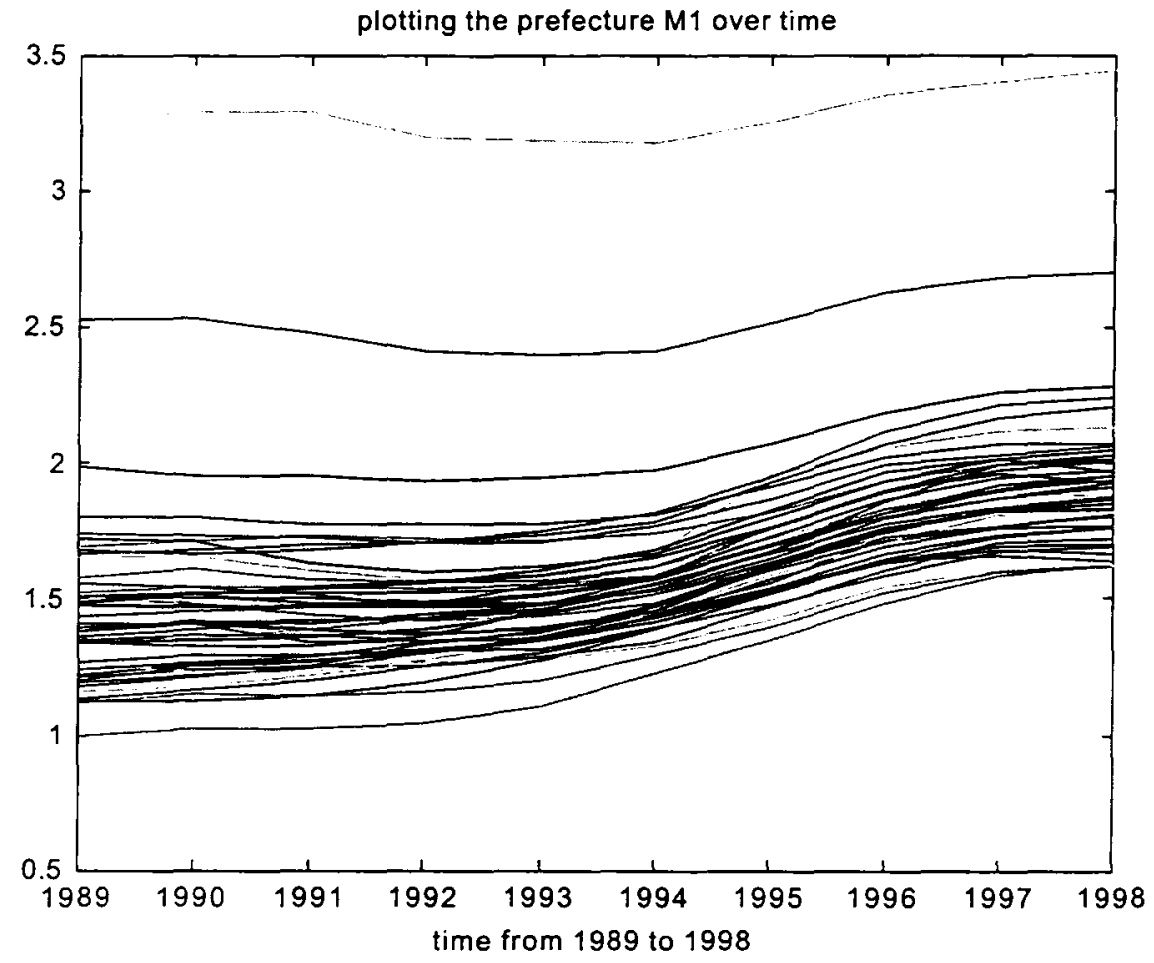


Figure 3 Plotting Prefecture Income For 47 Prefectures

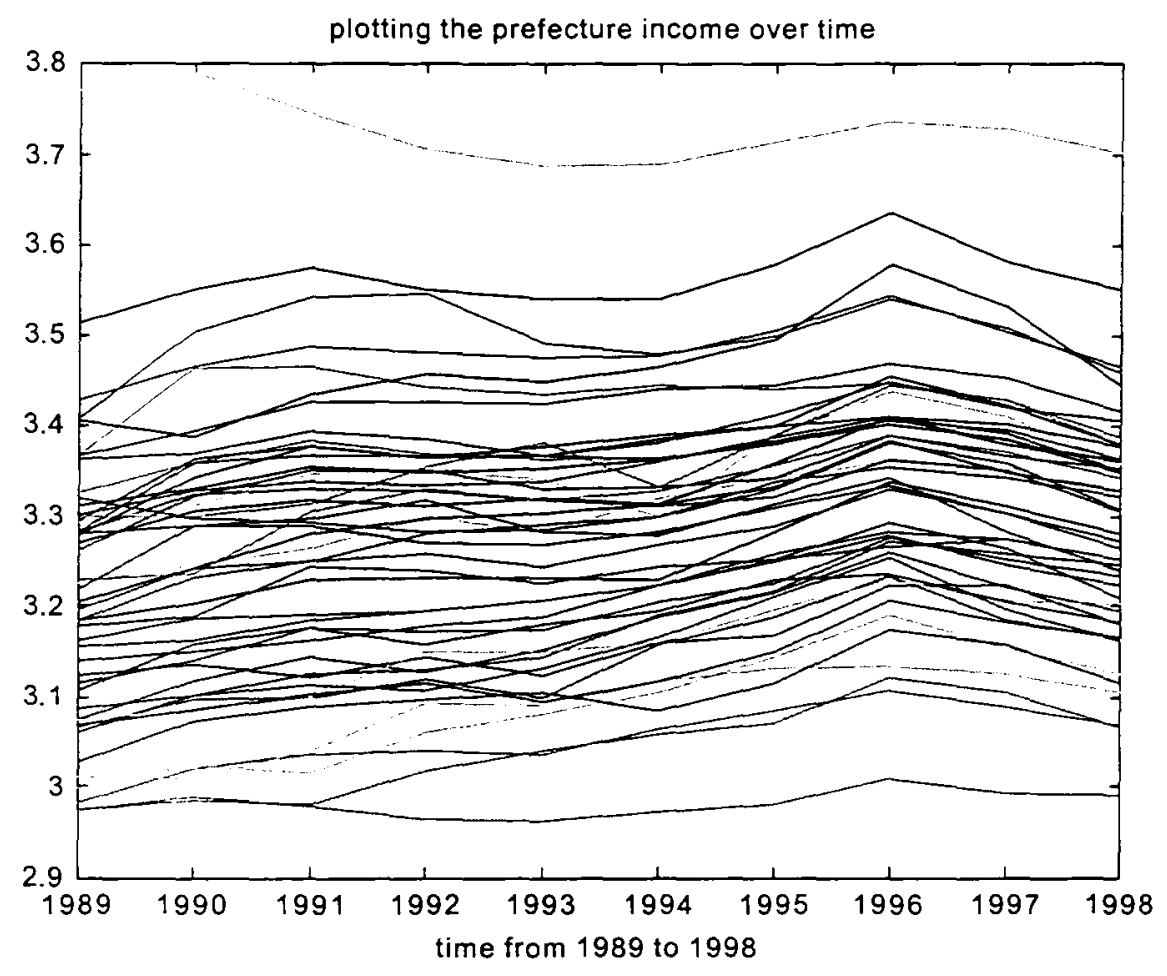


Figure 4a The Distribution of Lagged MF 1 Coefficients

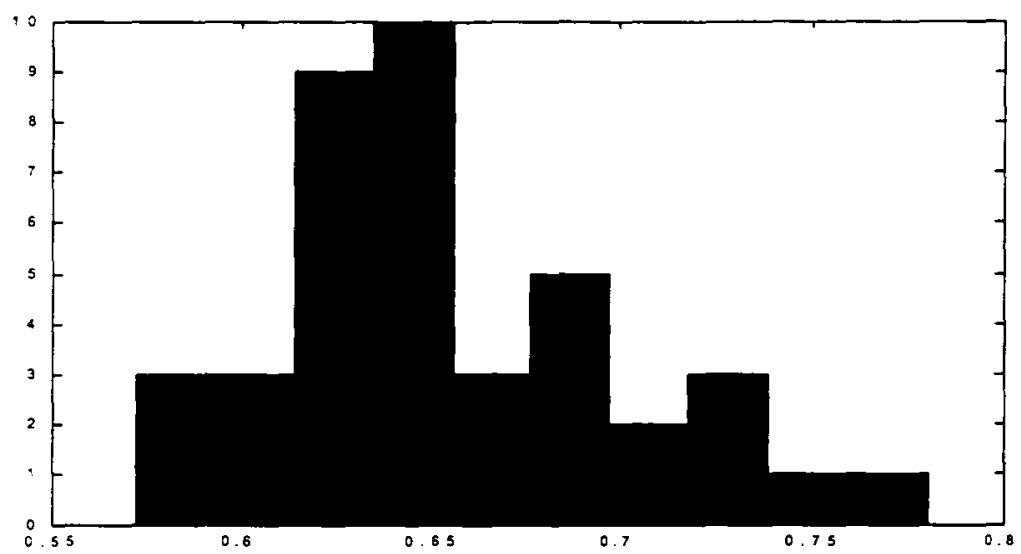

Figure $4 b$ The Distribution of lagged MF2 Coefficients

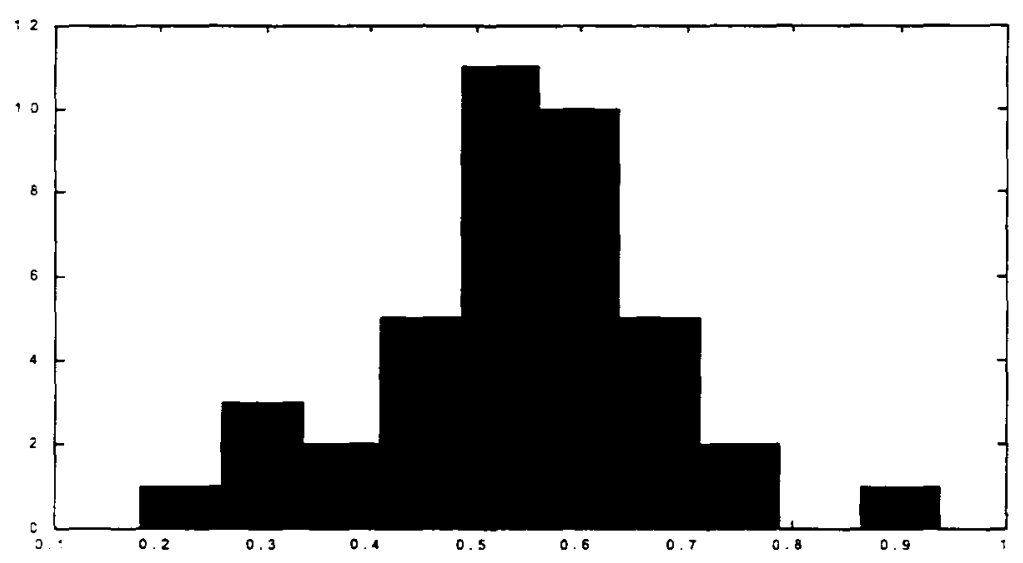


Figure 5 Prefecture Income Weight Distributions Over 1992 - 1997

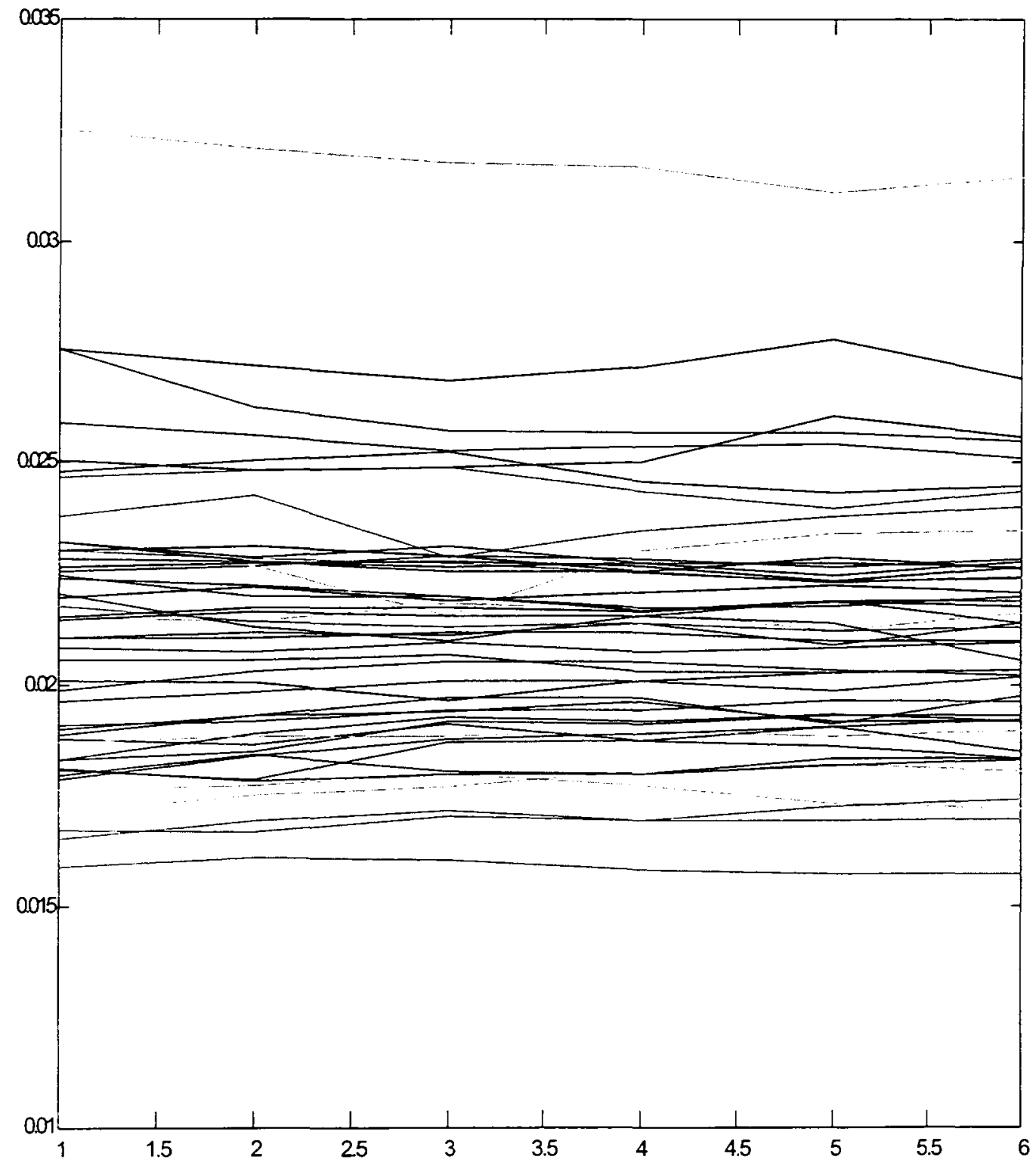


Figure 6 Histogram for Simulated M1(-1) Coefficients

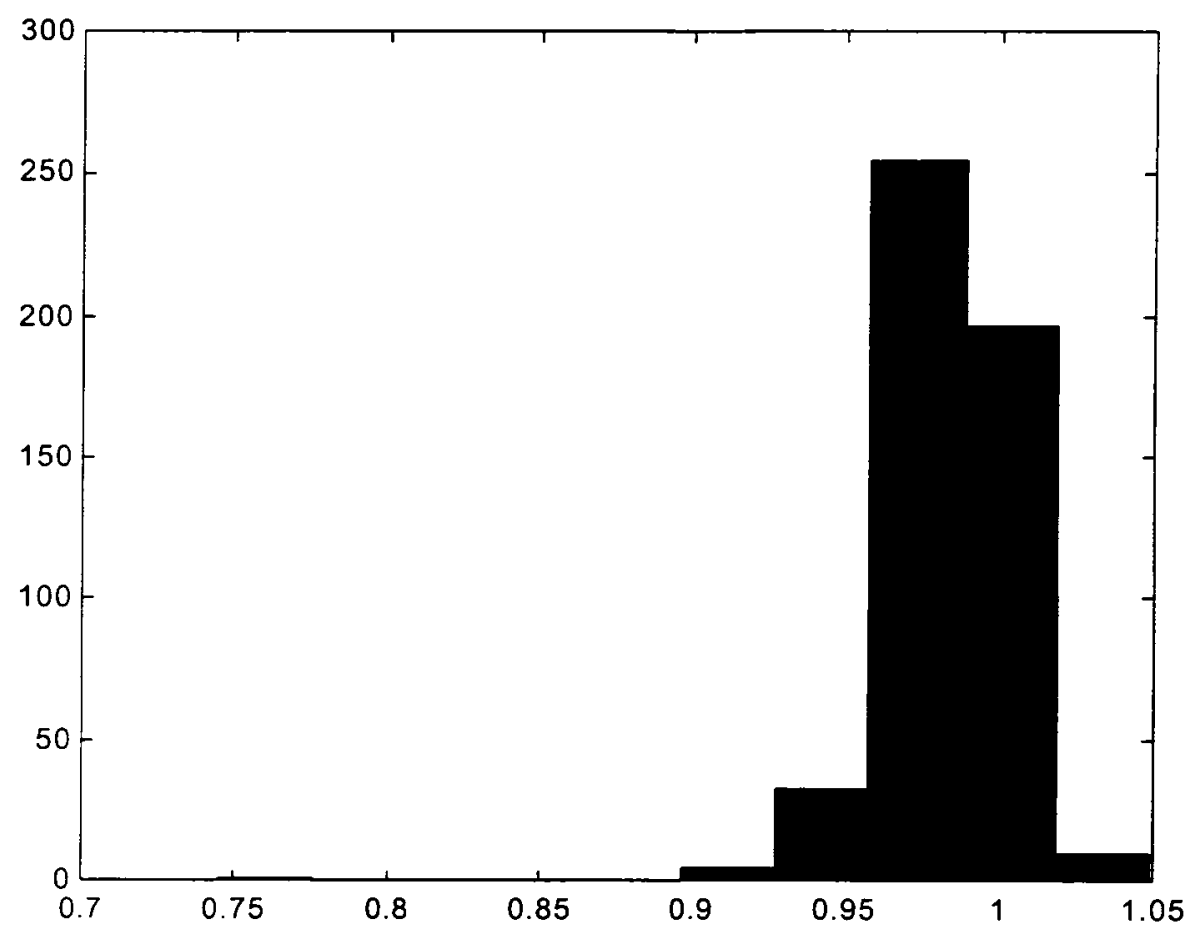


Figure 7 Histogram for Simulated M2(-1) Coefficients

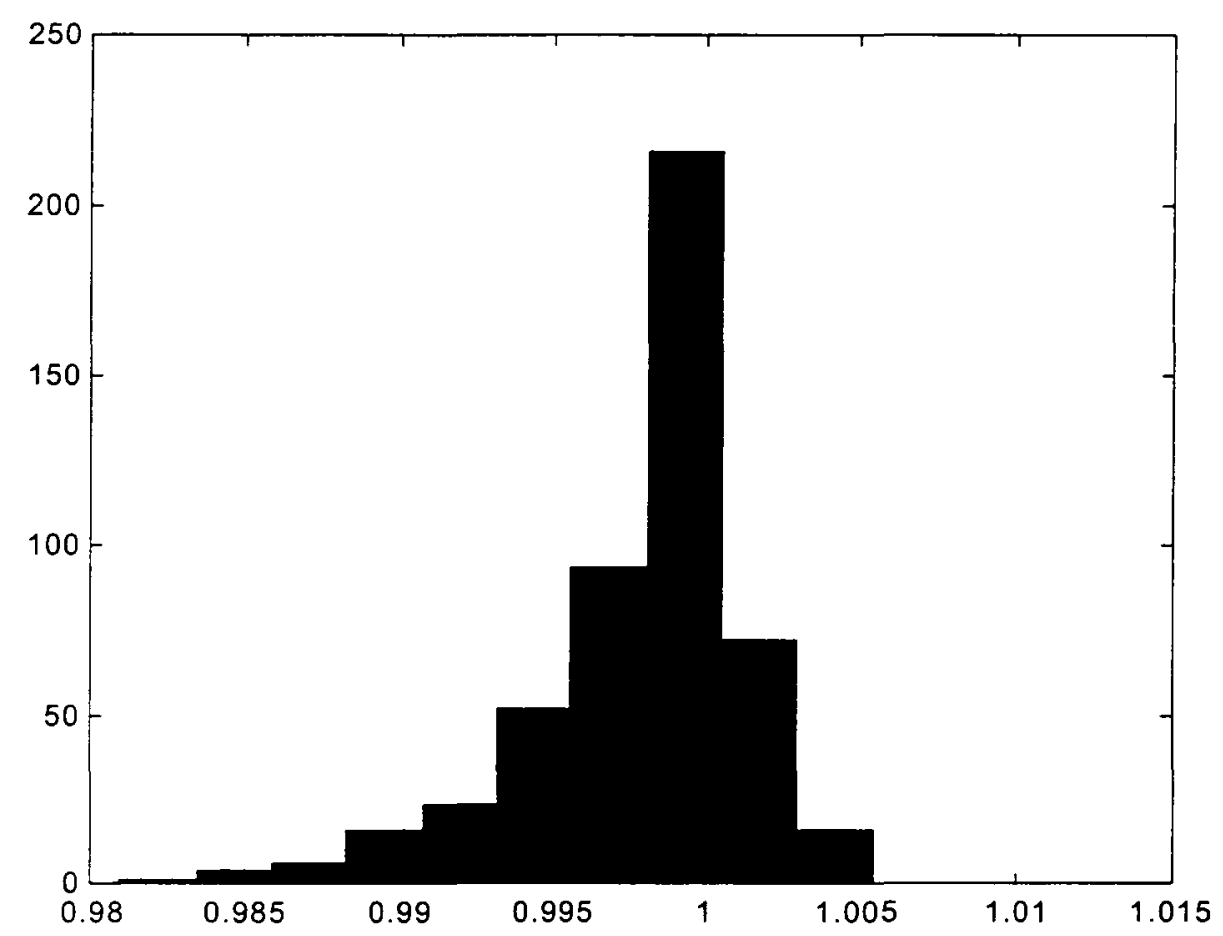


Figure 8 Histogram of Simulated M1(-1) Coefficients When Disaggregate Coefficients are Randomly Assigned

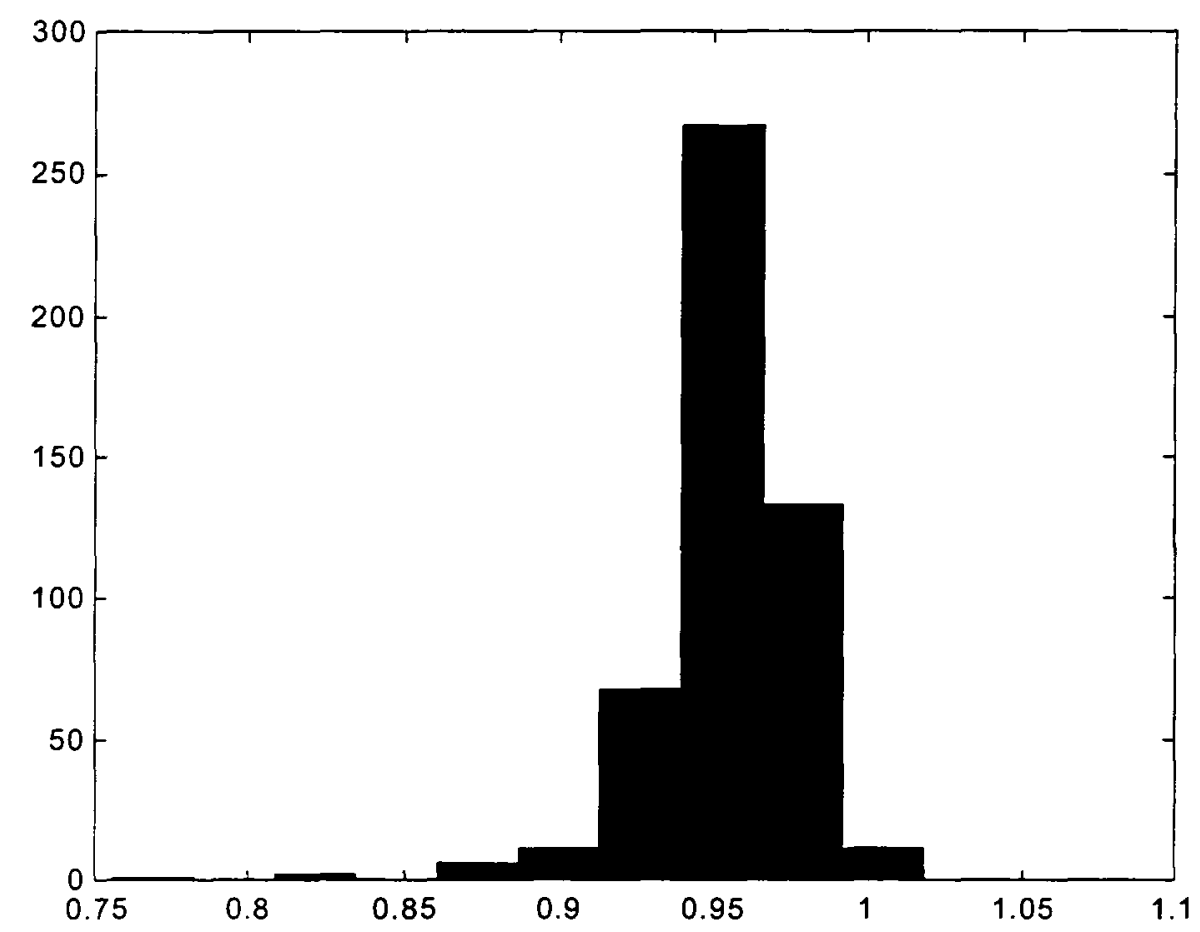


Figure 9 Histogram for M2(-1)

When Disaggregate Coefficients are Randomly Assigned

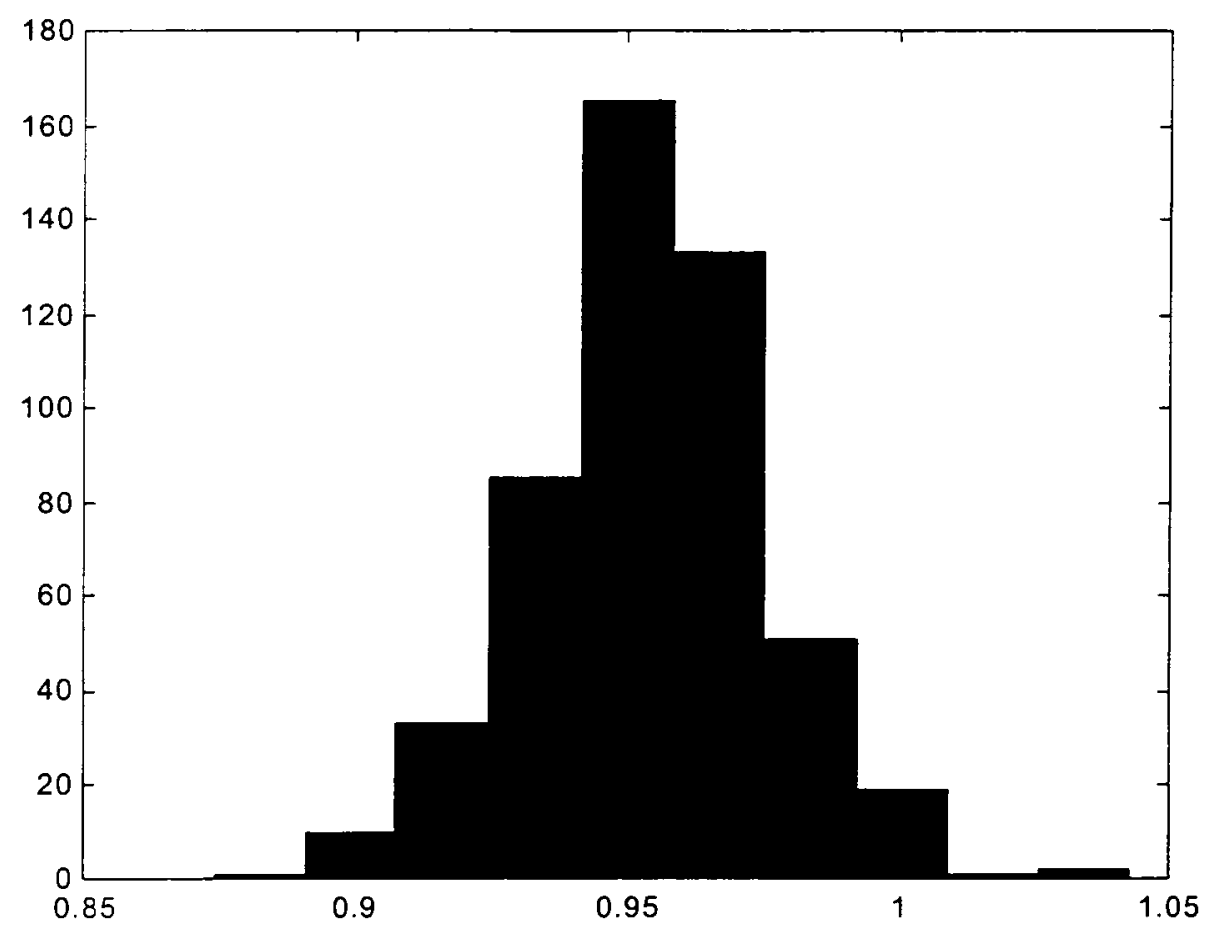


Figure 10 Simulated Responses of the "Real Aggregates" and Simulated Aggregates from Disaggregate Equations to Interest Rate Shock
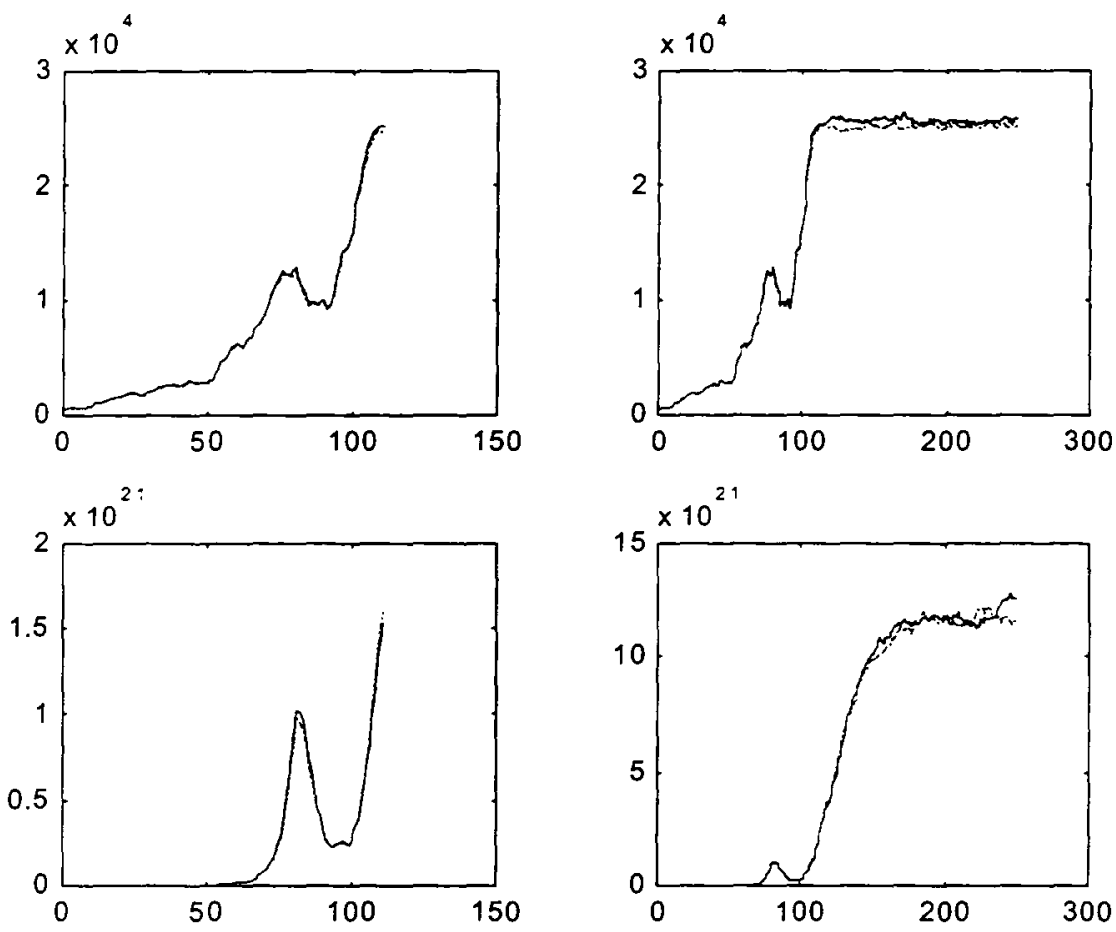
Figure 11 "Real Aggregates" and The Simulated Responses from the Aggregate and Disaggregate Equations
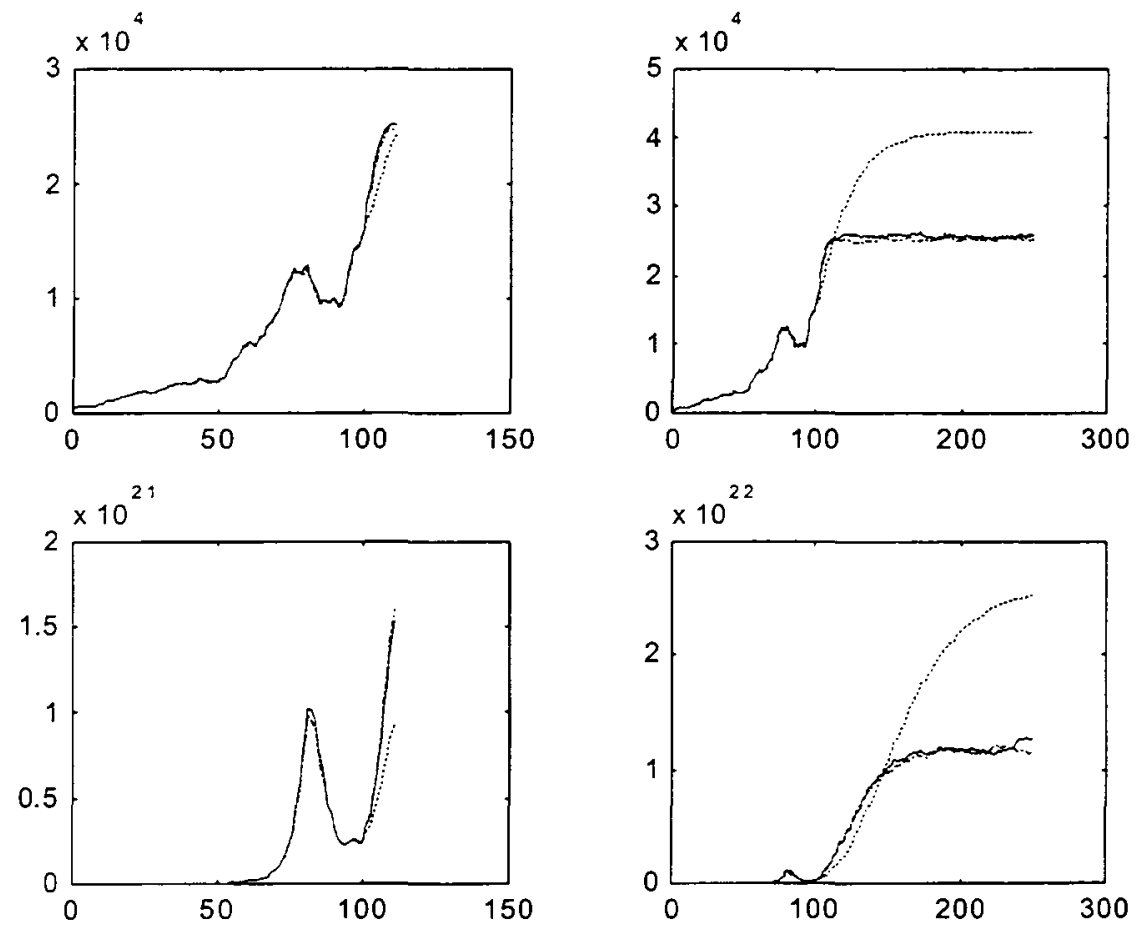
000317296

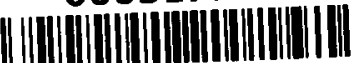


FUNDAÇĀO GETULIO VARGAS BIBLIOTECA

ESTE VOLUME DEVE SER DEVOLVIDO A BIBLIOTECA NA ULTIMA DATA MARCADA

\begin{tabular}{l|l|l|l}
\hline & & & \\
\hline & & & \\
\hline & & & \\
\hline & & & \\
\hline & & & \\
\hline & & & \\
\hline & & & \\
\hline & & & \\
\hline & & & \\
\hline & & & \\
\hline & & & \\
\hline & & & \\
\hline
\end{tabular}

N.Cham. P/EPGE SA H873a

Autor: Hsiao, Cheng.

Título: Aggregate vs disaggregate data analysis : a paradox

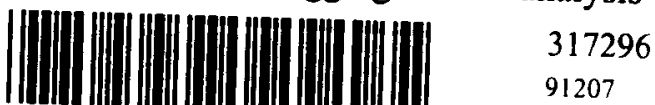

FGV - BMHS

$N^{\mathrm{v}}$ Pat: $: 317296 / 03$

91207

TOTECA

B I B L TO TEUE SINONSEN

MARIO HET:RIOUE SE VART'S

3172.96

$2 8 / 5 \longdiv { 2 0 0 3 }$ 